\title{
La distribución de competencias en materia de medio ambiente en Suiza
}

\author{
Jordi Jaria i Manzano \\ Profesor ayudante de Derecho Constitucional de la Universitat Rovira i Virgili
}

\begin{abstract}
Sumario: 1. INTRODUCCIÓN. 2. LA CONSTITUCIONALIZACIÓN DE LA PROTECCIÓN DEL MEDIO AMBIENTE EN SUIZA. UNA PERSPECTIVA HISTÓRICA. 3. LA COMPETENCIA FEDERAL EN MATERIA DE PROTECCIÓN DEL MEDIO AMBIENTE. 3.1. La determinación de la noción de medio ambiente en tanto que objeto de la competencia federal recogida en el artículo 74CF. 3.1.1. La solución constitucional a la determinación del contenido del medio ambiente como materia competencial: el medio ambiente natural. 3.1.2. Los problemas que plantea la noción de medio ambiente natural. 3.1.3. El medio ambiente como materia transversal. 3.2. El artículo 74CF como mandato al legislador federal y sus consecuencias en la definición funcional del título competencial en materia de protección del medio ambiente. 4. LA COMPETENCIA NORMATIVA DE LOS CANTONES EN MATERIA DE MEDIO AMBIENTE. 5. LA EJECUCIÓN DE LA POLÍTICA AMBIENTAL. 6. CONCLUSIONES.
\end{abstract}

\section{INTRODUCCIÓN}

La protección del medio ambiente va convirtiéndose progresivamente en uno de los núcleos temáticos más significativos de la investigación en el campo de la ciencia jurídica. Desde el final de la Segunda Guerra Mundial, se ha ido cobrando conciencia del alcance de los efectos transformadores de la actividad humana en el medio físico ${ }^{1}$. Esto ha dado lugar a la aparición el debate político, de manera remarcable, a partir de la segunda mitad de los sesenta, de una preocupación por las consecuencias de estas transformaciones y sus efectos en la vida de los seres humanos, preocupación de la que ha resultado la aparición de normas jurídicas sobre la protección del medio ambiente ${ }^{2}$. Este ámbito del Derecho aparece en el

\footnotetext{
${ }^{1}$ En relación con esto, vid., especialmente, Massimo Severo GianNINI, «"Ambiente”: saggio su diversi suoi aspetti giuridici», en Rivista Trimestrale de Diritto Pubblico, n. ${ }^{\circ} 2,1973$, p. 15 y ss. El autor italiano considera que, a partir de los años cuarenta, como proceso unido al aumento progresivo de las posibilidades de transformación del entorno a través de la actividad humana, se asiste a una toma de conciencia sobre la necesidad de incidir normativamente en el desarrollo de la actividad económica en tanto que modificadora del medio.

2 Antonio Pérez LuÑo, en «Artículo 45. Medio ambiente», en Óscar Alzaga VillaAmil, Comentarios a las Leyes Políticas (IV), Edersa, Madrid, 1984, p. 245, fija a finales de los años sesenta el nacimiento de un movimiento ecologista, mientras que Alexandre Kiss y Dinah SHELToN, en Manual of European Environmental Law, Cambridge University Press, Cambridge, 1993, p. 10, hacen notar que la toma de conciencia de la opinión pública sobre la cuestión dará lugar a que algunos estados comiencen a elaborar legislación respondiendo a estas inquietudes. Vid. también, en referencia a
} 
momento actual como uno de los sectores más dinámicos en su evolución y más importantes en sus efectos. Esto hace que no sea extraño que la preocupación por el medio ambiente haya llegado hasta los textos constitucionales, que, a partir de los años setenta, han empezado a hacer referencia a la cuestión, de la misma manera que explica el interés que se ha prestado al problema desde el ámbito del Derecho internacional público. El resultado final de todo ello es la consolidación de la preocupación por la protección del medio ambiente como uno de los aspectos más característicos de las sociedades contemporáneas.

La clara expansión en que se encuentra inmerso el Derecho ambiental y la importancia cada vez mayor que se otorga a las cuestiones de que se ocupa, colocan a los estudios sobre el tema en un lugar central de la reflexión actual de los juristas. Entre los múltiples campos dignos de atención en relación con la protección jurídica del medio ambiente, es evidente que debe destacarse, en los Estados compuestos, la problemática referida a la distribución de competencias en este terreno. Como dice Gerardo Ruiz-Rico, uno de los principales problemas que presenta la realización de la política ambiental es precisamente la definición exacta de las competencias que, en relación con ella, tienen reconocidas los diferentes poderes públicos territoriales ${ }^{3}$. En este sentido, debe tenerse en cuenta que la dificultad de definir un sector autónomo de límites claros para un objeto proteico como el medio ambiente condiciona el reparto de competencias ${ }^{4}$. Esta cuestión afecta a todos los Estados compuestos, que deben desarrollar la propia política ambiental teniendo en cuenta una estructura territorial que determina, al menos, dos niveles de gobierno relevantes. Por lo tanto, la clarificación de la distribución de competencias es un elemento de importancia fundamental para el futuro de las políticas ambientales.

Según nuestra opinión, el estudio de la ordenación del medio ambiente debe inscribirse en una perspectiva que la sitúe en el marco del modelo económico de que se dota una determinada comunidad. Así, la imbrica-

esto, Guillermo Escobar RocA, La ordenación constitucional del medio ambiente, Dykinson, Madrid, 1995, p. 15.

3 Vid. Gerardo Ruiz-Rico Ruiz, «La tutela dell'ambiente in Spagna», en Luca MezzetTi (ed.), I diritti della natura. Paradigmi di giuridificadone dell'ambiente nel diritro pubblico comparato, Cedam, Padua, 1997, p. 245. En el mismo sentido, vid. Carlo DESIDERI, «Il riparto delle atribuzioni per la tutela dell'arribiente», en Carlo DESIDERI (ed.), Autonomie territoriali e tutela dell'ambiente, Giufrè, Milán, 2001, p. 1.

${ }^{4}$ Vid. Guerino D’IGNAzIo, «La protezione della natura nell'ordinamento italiano», en MezzetTI, $I$ diritti della natura... op. cit., p. 33. 
ción del Derecho ambiental en el conjunto de disposiciones que disciplinan el funcionamiento del sistema económico parece la vía más adecuada para encontrar un camino que garantice la eficiencia de la protección del medio ambiente así como una inserción coherente en el ordenamiento jurídico. De esta manera, el medio ambiente deja de ser un motivo de interés lateral y, en demasiadas ocasiones, más bien anecdótico, para penetrar en la médula del modelo económico elegido por cada sociedad. Visto así, es evidente que la protección del medio ambiente puede ejercerse a través de múltiples competencias sectoriales. Sin embargo, como es sabido, en nuestro sistema la protección del medio ambiente tiene, además, la consideración de un título competencial específico (artículos 148.1.9 y 149.1.23CE, además de las múltiples referencias recogidas en los Estatutos de Autonomías). Esto dificulta un corte limpio en relación con las diferentes competencias que pueden afectar al medio ambiente.

En Suiza, el artículo 74 de la Constitució federal (en adelante, CF) recoge, aunque matizadamente, un título competencial específico en materia de medio ambiente y, por lo tanto, implica el mismo tipo de dificultades que se da en el caso español. Así pues, deberemos enfrentamos, en este trabajo, a la delimitación del significado específico de un título competencial en materia de protección del medio ambiente, considerando la dificultad que nos ofrece el carácter transversal de las políticas ambientales. Por lo tanto, debemos tener en cuenta, aparte de los problemas específicos que presentaría, por sí misma, la distribución de competencias en relación con una materia con tendencia a desplegarse a lo largo y ancho de todo el ordenamiento jurídico, el hecho de que se prevea un título competencial específico para ella. El hecho de que este problema sea compartido por los ordenamientos jurídicos suizo y español justifica, de entrada, que se preste un cierto interés a cómo se ha resuelto la partición competencial en esta materia en el caso de Suiza.

Por otra parte, más allá de compartir problemas de delimitación con el caso español, la elección del Derecho suizo como objeto se justifica por el hecho de hallarnos ante uno de los ordenamientos más avanzados en materia de protección del medio ambiente, circunstancia que es generalmente admitida y de la que la doctrina suiza acostumbra a hacerse eco ${ }^{5}$.

\footnotetext{
${ }^{5}$ Nos remitimos, por todos, a Peter KARLEN, «Neues Umweltrecht und seine Auswirkungen auf das Bauen», a Baurecht / Droit de la construction, n. ${ }^{\circ} 2.1998$, p. 40. Para contrastar esta idea, se puede consultar un balance bien documentado de la política y el Derecho ambientales en Suiza en el trabajo de Peter KNOEPFEL, «Zur Wirksamkeit des heutigen Umweltschutzrechts», Umweltrecht in der Praxis / Le Droit de l'environnement dans la pratique, 1994, pp. 201-236, que sigue siendo de interés a pesar del tiempo transcurrido desde su publicación.
} 
Debe tenerse en cuenta que, en tanto que se trata de uno de los países más desarrollados de Europa, Suiza lleva ya mucho tiempo explotando sus recursos a un nivel que, finalmente, ha determinado un replanteamiento de su modelo económico, lo que ha incidido en la formulación de políticas ambientales ambiciosas tanto a nivel cantonal como federal. La aparición de problemas ambientales serios ha sucedido en Suiza de una manera precoz y esto ha dado lugar a la necesidad de ordenar las actividades económicas con relevancia ambiental y, por lo tanto, al desarrollo del Derecho ambiental ${ }^{6}$.

No podemos perder de vista, por otra parte, que Suiza ha tomado parte en todas las conferencias referidas a los aspectos globales de la protección del medio ambiente, sus relaciones con el desarrollo y los retos que, al respecto, representan las nuevas tecnologías, convirtiéndose, a pesar de ser un estado pequeño, en una voz autorizada en el ámbito internacional en relación con estas cuestiones. Así, Suiza ha proporcionado al desarrollo de la protección del medio ambiente a nivel internacional un impulso no desdeñable ${ }^{7}$. Por ejemplo, puede destacarse, la política suiza en relación con la negociación de instrumentos internacionales relativos al cambio climático $^{8}$. Esta actitud activa a nivel externo ha tenido como resultado una actitud respetuosa del Gobierno suizo con los compromisos internacionales adoptados en el terreno del Derecho ambiental en el desarrollo de sus políticas a nivel interno. En este sentido, debe destacarse la implementación de una política activa en relación con el desarrollo sostenible, que se ha convertido en una de las prioridades de Suiza a partir de la cumbre de Río de 1992, como muestran, por otra parte, los artículos 2 y 73 de la nueva Constitución federal de $1999^{9}$.

En última instancia, debemos tomar en consideración el hecho de que, en realidad, Suiza es el primer estado que se preocupó, en su momento, a nivel constitucional por la distribución de competencias en materia de medio ambiente con la introducción del artículo 24septies mediante la reforma constitucional aprobada el 6 de junio de 1971. Esto hace que, en el caso de Suiza, se haya desarrollado una importante praxis en esta mate-

6 Vid. Anne PetitPierre-Sauvain, Environmental Law in Switzerland, Kluwer-Stämpfli, La HayaLondres-Boston-Berna, 1999, p. 20 y ss.

7 Vid. KARLEN, «Neues Umweltrecht...» op. cit., p. 40.

8 Sobre esto, vid. Helene KELLER, «Klimaregime an der Schwelle zum 21. Jahrhundert. Durchbruch dank ökonomischer Instrumente oder Aushöhlung durch Flexibilisierung?», en Umweltrecht in der Praxis / Le Droit de l'environnement dans la pratique, 1999, p. 379 y ss.

9 Vid. PetitPierre-Sauvain, Environmetal Law... op. cit., pp. 20 y 21. 
ria, con el factor añadido de la larga experiencia suiza en cuanto a la distribución territorial del poder. Este último elemento, junto con las características propias del sistema político suizo, contribuye a que la práctica en el reparto de funciones en la política ambiental haya sido más bien consensual, por oposición al modelo conflictual que se ha desarrollado en España desde la Constitución de 1978, con una fuerte intervención del Tribunal Constitucional en la definición de los ámbitos de poder del Estado y las Comunidades Autónomas ${ }^{10}$.

\section{LA CONSTITUCIONALIZACIÓN DE LA PROTECCIÓN DEL MEDIO AMIBIENTE EN SUIZA. UNA PERSPECTIVA HISTÓRICA ${ }^{11}$}

En 1971, el pueblo y los cantones aprobaron la reforma de la Constitución federal que introducía el artículo 24septies, una disposición que consagraba a nivel constitucional la protección del medio ambiente y asignaba la competencia para regular su régimen jurídico al legislador federal ${ }^{12}$. La introducción de la citada disposición era la culminación de una evolución histórica a través de la que la Confederación había ido ampliando su margen competencial en relación con las materias referentes a la normación de la relación entre los seres humanos y su entorno. Este fenómeno, de hecho, se correspondía con el proceso de ampliación competencial que se ha dado particularmente en Suiza, pero que, de hecho, es común a todos los estados descentralizados clásicos, en relación con la asunción por parte del poder central de nuevas facultades a causa de la extensión de las atribuciones de los poderes públicos como consecuencia de la recepción

\footnotetext{
${ }^{10}$ En cuanto a las características del sistema político suizo que posibilitan la baja conflictividad entre el centro y la periferia, vid. Remedio SÁnCHEZ FerRIZ y María Vicenta GARCía Soriano, Suiza. Sistema político y Constitución, Centro de Estudios Constitucionales, Madrid, 2002, especialmente, p. 69 y ss., así como mi trabajo, «El federalismo suizo. Una respuesta a una sociedad plural», en Revista Vasca de Administración Pública / Herri-Arduralaritzako Euskal Aldizkaria, n. ${ }^{\circ} 61$ (I), septiembre-diciembre 2001, pp. 89-136.

${ }^{11}$ De manera general, sobre la evolución de las competencias federales en esta materia, vid. Leo Schürmann y Peter HÄNNI, Planungs-, Bau- und besonderes Umwellschutzrecht, Stämpfli, Berna, 1995, p. 8 y ss.

12 En general, sobre esto, Vid. Beatrice Wagner PfeIfER, Umweltrecht I, Schultess, Zúrich, 1999, p. 21. Sobre el proceso de introducción de este artículo en la Constitución federal, vid. Karl WEGMANN, «Der Umweltschutz als Aufgabe von Verfassung und Gesetz», en Zeitschrift de bernischen Juristenvereins, 1971, p. 293 y ss. Para tener una visión más o menos contemporánea de lo que representó la introducción de la citada disposición, vid. la monografía de Peter Kalt, Wesen und Bedeutung von Art. 24 septies (Umweltschuizartikel) der Bundesverfassung, Konkordia, Winterthur, 1977. Más recientemente, vid. Chistoph ERRASs, Katastrophenschutz, Universitätsverlag, Friburg, 1998 , p. 62 y ss.
} 
de la cláusula del Estado social ${ }^{13}$. En este contexto, debemos destacar que, desde la aprobación de la Constitución federal de 1874, la federación ha ido ampliando su margen de actuación ${ }^{14}$. Este fenómeno de ampliación competencial progresiva a lo largo del siglo XX coincide en un momento determinado con la preocupación creciente en relación con las cuestiones ambientales, preocupación que reclama la intervención de los poderes públicos. De este modo, se dibuja en este contexto el escenario para la asunción de competencias ambientales por parte de la federación. En este sentido, deberemos tener en cuenta que el artículo 24septies constituye el eje central de un conjunto de preceptos que tienen incidencia en el diseño de la política ambiental y que atribuyen un margen amplio actuación a la federación, como veremos más adelante.

La asunción por parte del poder central de competencias relacionadas con el medio ambiente durante los últimos decenios es, de hecho, un fenómeno común a los distintos estados descentralizados, del mismo modo que, anteriormente, había sucedido con los títulos competenciales que tenían relación con la implantación del Estado social. Por ejemplo, en Estados Unidos, otro de los estados con una legislación ambiental más avanzada y con mayor tradición, idénticamente a lo que sucede en Suiza y de conformidad con la segunda enmienda de la Constitución, la federación sólo dispone de las competencias legislativas que le han sido atribui-

13 Vid., entre otros, Gérard MARCOU, «L'évolution récente du fédéralisme allemand sous l'influence de l'intégration européeme et de l'unification», en Revue de Droit Public, 1995, n. ${ }^{\circ}$ 4, p. 883; y Javier TAJADURA TEJADA, El principio de cooperación en el estado autonómico, Comares, Granada, 1998 , p. 43. Por supuesto, este fenómeno de ampliación de competencias del poder central presenta matices. En este sentido, como remarca Pablo SANTOLAYA MACHETTI, en su estudio ya clásico Descentralización y cooperación, Instituto de Estudios de Administración Local, Madrid, 1984, p. 75 y ss., la ampliación de atribuciones del poder central se produce en el marco de una ampliación general de las atribuciones de los poderes públicos y, por lo tanto, no necesariamente en perjuicio de los entes subcentrales, que, de hecho, también ampliarían su margen de actuación respecto al Estado liberal clásico. De todas maneras, en sistemas federales como el americano o el suizo, en que las competencias no atribuidas al poder central por la Constitución permanecen en manos de los estados miembros, lo cierto es que la atribución de nuevas competencias al poder central, sea a través de la reforma constitucional, sea por vía interpretativa de la norma fundamental, significa una reducción teórica de las competencias de los entes subcentrales, que, de hecho, las pierden aunque nunca antes las hubieran ejercido. Otra cosa es que el crecimiento del ámbito de lo público comparten la actuación de los entes subcentrales en terrenos que, hasta aquel momento, habían quedado fuera de la actuación de los poderes públicos, pero, en cualquier caso, lo hacen ejerciendo una competencia general originaria, sólo limitada por la Constitución federal. Sobre el proceso de centralización de los estados federales en relación con otros rasgos de su evolución, como, por ejemplo, la eclosión del llamado federalismo cooperativo, vid., por todos, Enric FossAs, «La Comunitat: Autònoma de Catalunya en la Constitució del 1978», en Mercè BARCELó y Joan VinTro (coords.), Dret Públic de Catalunya, Cedecs, Barcelona, 2001, pp. 75 y 76.

14 Vid., sobre sobre esta evolución, Jean-François AUBERT, en Traité de droit constitutionnel suisse I, Ides et Calendes, Neuchâtel, 1967, p. 53. 
das por la misma. La Constitución, sin embargo, no ha introducido ninguna habilitación expresa para la federación en el sentido de permitirle legislar en materia de protección del medio ambiente. Ahora bien, encontrando apoyo en la célebre Interstate Commerce Clause (recogida en el artículo 1.8.3 de la Constitución), el Tribunal Supremo ha permitido al Congreso extender sus competencias legislativas, de modo que la federación ha podido intervenir en la regulación de numerosos dominios de la vida económica y social, entre los que se halla la protección del medio ambiente ${ }^{15}$. Así, si las primeras regulaciones en este campo provenían de los estados federados, el Congreso, desde prácticamente, finales de la década de los sesenta, con la National Environmental Policy Act (conocida habitualmente por sus siglas, NEPA), ha votado varias leyes en este terreno ${ }^{16}$.

En realidad, es justamente hacia el final de la década de los sesenta, cuando la aparición de la preocupación por la protección del medio ambiente en las sociedades más avanzadas y la necesidad de normas jurídicas que den satisfacción a esta necesidad hacen que se plantee, en los estados compuestos, el problema sobre quién debe ejercer la competencia en este sector. En un primer momento, fueron, como decíamos en el caso de Estados Unidos, los entes subcentrales los que se hicieron cargo de responder a las demandas de protección del Medio ambiente ${ }^{17}$. De hecho, según una de las más importantes especialistas suizas en el campo del

\footnotetext{
${ }^{15}$ En relación con la Interstate Commerce Clause y otras cláusulas constitucionales que han permitido la intervención federal en materia ambiental, vid. Gerardo RuIz-Rico RuIz, «Constitución y medio ambiente en los Estados Unidos: elementos de referencia para conocer el régimen jurídico de los parques nacionales», en Gerardo Ruiz-Rico Ruiz (coord.), Derecho comparado del medio ambiente y de los espacios naturales protegidos, Comares, Granada, 2000, p. 406. En la literatura americana, Nancy K. KUBASEK y Gary S. SILVERMAN presentan un análisis introductorio a la Interstate Commerre Clause, en Environmental Law, Prentice Hall, Upper Saddle River, 2000 (3a edición), p. 27 y ss. En realidad, en general, la federación ha ido adquiriendo un papel clave en la creación del Derecho ambiental en la mayoría de sistemas federales, basándose en muchos casos en normas constitucionales que no estaban pensadas para atribuirle competencias en este terreno. Por ejemplo, en Austria, donde la protección del medio ambiente no ha sido recogida explícitamente como título competencial en la Constitución federal, el legislador federal ha elaborado la mayor parte del Derecho ambiental en base a las competencias sectoriales que tiene atribuidas, componen de manifiesto Heinz MaYer y Christian Schmelz, en «Environmental Law in Austria. The Environmental Law System», en N.S.J. Koeman (ed.), Environmental Law in Europe, Kluwer, La HayaLondres-Boston, 1999, pp. 31 y 32.

16 Vid., en relación con esto, Yves Nicole, L'érude d'impact dans le système fédéraliste suisse. Étude de droit fédéral et de droit vaudois, Payot, Lausanne, 1992, p. 25. Sobre la NEPA, vid. la exposición sintética que hacen KUBASEK y SILVERMAN, en Environmental Law op. cit., p. 130 y ss.

17 En este sentido, en Estados Unidos, los Estados e, incluso, los entes locales fueron los principales protagonistas de la política (proto-)ambiental hasta fines de los años sesenta, como pone de manifiesto RUIZ-RICo RUIZ, en «Constitución y medio ambiente...» op. cit., p. 407.
} 
Derecho ambiental, Anne PetiTPierre, en un sistema federal, la protección de los recursos naturales y del medio ambiente debería corresponder, en primer lugar, a los estados miembros, debiendo ser subsidiaria la intervención del poder central ${ }^{18}$.

Debemos preguntamos, pues, en el marco de la confluencia de la preocupación por la protección del medio ambiente, a la que, en principio, reaccionan los entes subcentrales, y de la ampliación de las competencias del poder central a lo largo del siglo Xx en los distintos estados federales clásicos, como es que, en un momento determinado, que, de hecho, puede situarse en el cambio de década entre los sesenta y los setenta, la federación asume atribuciones ciertamente amplias en el marco de la política ambiental ${ }^{19}$. La respuesta a esta pregunta debe buscarse en la dimensión

\footnotetext{
18 Vid. PetitPierre-Sauvain, Environmental Law... op. cit., p. 33.
}

19 En el caso de los Estados Unidos, debería fijarse el momento determinante en esta evolución en la creación de la Environmental Protection Agency (EPA). A pesar de todo, sin embargo, los estados miembros continuaran teniendo un papel activo en la política ambiental. Sobre esto, vid. RuIz-Rico RuIZ, «Constitución y medio ambiente...» op. cit., p. 407 y ss. Aparte del caso de Estados Unidos, pueden considerarse otros ejemplos, así, Italia, por citar un sistema más o menos próximo al español. En este caso, vid., en relación con la evolución de los últimos años, D'IGNAZIo, «La protezione della natura...» op. cit., p. 54 y ss. En realidad, como nota este autor en una versión actualizada del trabajo citado, a saber, «La tutela del ambiente y la protección de las áreas naturales en Italia», en Ruiz-Rico Ruiz, Derecho comparado... op. cit. (traducción al castellano de Claudia Herrera Castaño), p. 167 y ss., la nueva sensibilidad ambiental del Tribunal Constitucional italiano que se manifiesta durante los años ochenta da lugar a un proceso de recentralización en la materia, que se produce tanto en los pronunciamientos del mismo Tribunal como en la legislación (así, la Ley 431/1985, llamada Ley Galasso). A pesar de ello, el mismo autor cree que, de todas maneras, en los últimos años, la jurisprudencia constitucional ha reconocido un papel más activo a las regiones italianas en materia ambiental, según concluye en op. cit., p. 170. Por otra parte, debe tenerse en cuenta la aprobación de la Ley 59/1997, que, aplicando el principio de subsidiariedad, ha impulsado nuevamente la descentralización en Italia. Vid., sobre esto, op. cit., p. 191 y ss. Sin embargo, debe notarse, como conclusión, que la reforma del título V de la Constitución italiana aprobada en 2001 atribuye al Estado central, de acuerdo con la nueva redacción del artículo 117, la competencia exclusiva en relación con la tutela "dell'ambiente, dell'ecosistema e dei beni culturali», reafirmándose nuevamente la tendencia centrípeta. Nos referiremos también al caso de Canadá, donde se ha aceptado significativamente la ampliación de la jurisdicción federal en materias cuyo carácter único e indivisible se considera base suficiente para justificar una legislación uniforme, teniendo en cuenta su dimensión estatal. Éste sería el caso de algunos aspectos de la política ambiental, como la lucha contra la contaminación. En este sentido se ha pronunciado la jurisprudencia a nivel federal, según explica Maurice CROISAT, en Le fédéralisme dans les démocraties contemporaines, Monchrestien, París, 1999 ( $3^{\text {a }}$ edición), p. 45. En relación con España, Santiago MuÑoz MaChado, en «La distribución de competencias entre el Estado, las Comunidades Autónomas y las corporaciones locales en materia de medio ambiente», en Documentación Administrativa, n. ${ }^{\circ}$ 190, abril-junio 1981, p. 351 y ss., ponía de manifiesto que se había producido a lo largo de los tiempos anteriores a su trabajo un proceso de centralización de las políticas públicas en materia de medio ambiente, que habían estado originariamente en manos de la Administración local. Sin embargo, la implantación del Estado de las autonomías habría invertido la tendencia posteriormente. 
de los problemas a los que los poderes públicos se enfrentan en este ámbito. Así pues, este proceso de apoderamiento de las instancias centrales, en Suiza se ha justificado acudiendo al argumento de que, cuando los problemas no pueden ser resueltos a nivel local y existe la necesidad de una aproximación común a nivel de todo el territorio de la Confederación, ésta debe intervenir ${ }^{20}$. De hecho, debe tenerse en cuenta que la mayor parte de los problemas ambientales tiene hoy día naturaleza transfronteriza, esto es, pueden tener su origen, total o parcialmente, en un territorio y producir sus efectos en los territorios vecinos ${ }^{21}$. Este carácter transfronterizo de los problemas ambientales, que es el fundamento de la atención que el Derecho internacional presta a la protección del medio ambiente, justificaría, en el ámbito territorial del Estado, el tratamiento unitario de la cuestión ${ }^{22}$. Así pues, la necesidad de una aproximación común, que, por otra parte, es una expresión bien clara del principio de subsidiariedad, constitucionalizado en la revisión total de la Constitución federal suiza de 1999 (art. 42.2CF $)^{23}$, se hallaría en el fundamento del conjunto de competencias en materia de medio ambiente de que disponen la Confederación en este momento. En definitiva, es a partir de la necesidad de la intervención subsidiaria de la Confederación para afrontar problemas que los cantones no pueden combatir por sí mismos de manera suficientemente eficaz que se introduce el artículo 24septies en la Constitución federal, disposición que,

\footnotetext{
20 Vid. Petitpierre-Sauvain, Environmental Law... op. cit, p. 33.
}

21 Este hecho ha sido puesto de manifiesto por infinidad de autores. Citemos, a modo de ejemplo, Mercedes Franco DEL Pozo, El derecho humano a un medio ambiente adecuado, Universidad de Deusto, Bilbao, 2000, p. 60; Philip KUNIG, «Grenzüberschreitender Umweltschutz - Der Einzelne im Sclnittpunkt von Verwalungsrecht, Staatsrecht und Völkerrecht» en Werner ThIEME (ed.), Umweltschutz im Recht, Duncker \& Humblot, Berlín, 1988, pp. 213-232; Manuel PIÑAR DíAZ, El derecho a disfrutar del medio ambiente en la jurisprudencia, Comares, Granada, 1996, p. 30; Reiner Schmid, Einführung in das Umweltrecht, Beck, Munic, 1992 (3 ${ }^{\text {a }}$ edición), p. 154; y WAGNER PFEIFER, Umweltrecht.. op. cit., p. 19.

22 En realidad, éste es uno de los argumentos más utilizados a la hora de justificar las competencias del poder central en materia de protección del medio ambiente y, por lo tanto, para excluir en ocasiones la acción de los entes subcentrales. Como muestra representativa de cómo suele utilizarse el argumento del carácter transfronterizo de los problemas ambientales en este contexto podemos remitirnos a Alberto Ricardo DALLA VIA, que, en «Derecho ambiental en Argentina: la reforma constitucional de 1994 y el medio ambiente», en RUIZ-RICo RuIZ, Derecho comparado... op cit., p. 306, afirma: «El medio ambiente es infragmentable desde el punto de vista geográfico, por lo tanto es necesaria una reglamentación que establezca una protección indivisible (...)». Vid. también MuÑOZ MACHADO, en «La distribución de competencias...» op. cit., p. 370.

23 Vid. Urs Thalmann, «Subsidiaritätsprinzip und Kompetenzverteilung», a Thomas Fleiner, Peter Forster, Alexander Misic y Urs Thalmann (eds.), Die neue schweizerische Bundesverfassung. Föderalismus, Grundrechte, Wirtschaftsrecht und Staatsstruktur /La nouvelle Constitutión suisse. Fédéralisme, droits fondamentaux, droit économique et structure de l'Etat, Helbing \& Lichtenhahn, Basilea-Ginebra-Múnich, 2000, p. 162 y ss., para un comentario sobre el principio de subsidiariedad tal como queda recogido en la nueva Constitución. 
con algunas modificaciones, ha pasado a ser el artículo 74 en el nuevo texto de 1999.

La Constitución federal acostumbra a atribuir las materias que la comunidad política considera más importantes a la Confederación. Esto sería la causa de que, precisamente por la atención creciente que despertaba en la opinión pública la protección del medio ambiente, esta materia se convirtiese en competencia federal con la modificación constitucional aprobada el 6 de junio de $1971^{24}$. Es pues la dimensión transcantonal de la materia, de manera similar a como sucede con las competencias de carácter económico y social asumidas por la federación durante las primeras décadas del siglo Xx, lo que explica la constitucionalización de la materia y la asignación de una competencia a la federación, que, de esta manera, puede empezar a actuar en un campo que, hasta aquel momento, había estado reservado a los cantones, paralelamente a lo que está sucediendo, en aquel momento, en Estados Unidos.

La necesidad de una regulación común en sectores que, a partir de la eclosión de la preocupación por el medio ambiente en el debate público, adquirirán una dimensión ambiental, se manifestó, sin embargo, mucho antes. Ya en 1874, la nueva Constitución federal incluyó una competencia federal en materia de caza y pesca, a partir de la que se elaborará una ley federal en el año siguiente. En 1897, la Confederación recibió, como consecuencia de una reforma constitucional, la alta inspección en la política de canalizaciones y montes, de la que deriva la Ley federal de Montes de 1902. Por otra parte, debe notarse que, desde 1877, existía una Ley federal de Policía del Agua, aunque la competencia federal en materia de aguas, como veremos seguidamente, se vio modificada con una nueva reforma constitucional a principios de los años cincuenta del siglo pasado ${ }^{25}$. Originariamente, sin embargo, estas competencias no pueden calificarse como genuinamente ambientales, ya que la aparición de una auténtica preocupación por la protección del medio ambiente es posterior.

En este sentido, puede afirmarse que la aparición de las cuestiones ambientales en el debate político en Suiza, como en gran parte de Occidente, no puede comenzar a rastrearse hasta finales de la década de los

24 Vid., en este sentido, Jürg HoFER, «Das kantonale Umweltschutzrecht», en Kurt JenNy, Alex Achermann, Stephan Mathis y Lukas Otт (eds.), Staats- und Verwaltungsrecht des Kanton BaselLandschaft, Vertrag des Kanton Basel-Landschaft, Liestal, 1998, p. 395.

${ }^{25}$ En relación con el proceso de asunción de competencias por parte de la Confederación en sectores relacionados con el medio ambiente durante el último tercio del siglo XIX, vid. PETITPIERRE-SAUVAIN, Environmental Law.. op. cit., p. 33. 
cincuenta. El punto de inflexión, en Suiza, podría situarse en la reforma constitucional de 1953, que representó la atribución a la Confederación de una competencia sobre la polución de las aguas mediante la introducción del antiguo artículo $24 q_{\text {qater }}{ }^{26}$. Hasta aquel año, como pone de manifiesto Anne Petitpierre, no había habido ninguna ley federal de importancia comparable a la Ley de Montes de 1902 en el ámbito de la ordenación de los recursos naturales, lo que convierte en especialmente significativa la reforma constitucional de 1953, ya que constituye el punto inicial de un período en que la progresiva sensibilización de la opinión pública en relación con las cuestiones ambientales va a dar lugar a una serie de disposiciones constitucionales que van a representar una modificación substancial del marco jurídico de las relaciones entre el ser humano y su entorno, cuyo punto culminante será la introducción del ya citado artículo 24 septies en la Constitución federal. Progresivamente, se va desarrollando un cambio de las mentalidades que va configurando una nueva sensibilidad por los problemas relativos a la relación entre los seres humanos y el medio ambiente, sensibilidad que empezará a hacerse evidente durante la década de los sesenta, en que puede hablarse ya de una auténtica preocupación por el medio ambiente.

Dejando atrás la reforma constitucional de 1953, deben destacarse como hecho significativo, por lo que nos dice de la evolución de una conciencia ambiental incipiente, las dos iniciativas populares de reforma de la Constitución federal votadas en 1954 y 1955, centradas ambas, fundamentalmente, en la problemática planteada respecto a la alteración del entorno natural del valle del Rhin, afectado, en particular, por una convención germano-suiza sobre la explotación de las famosas cataratas del río, que se encuentran en el tramo que hace de frontera entre Alemania y Suiza. A partir del debate generado acerca de estas iniciativas se hizo evidente el conflicto de intereses que podía aparecer entre puntos de vista tendentes a un grado muy alto de protección del entorno y la racionalidad económica que rige la explotación de los recursos naturales. La primera de las iniciativas a que nos referimos, llamada de la Rheingau, fue ampliamente rechazada el 5 de diciembre de 1954, mientras que la segunda, referida a la protección de determinados lugares de interés natural y destinada a evitar la sobreexplotación de los recursos, lo fue el 13 de mayo del año siguiente. A pesar del rechazo, el debate quedó abierto. De hecho, la segunda de las iniciativas, que cuestionaba la ratificación de los tratados internacionales y el estatuto de las compañías hidroeléctricas, fue diso-

\footnotetext{
26 Vid. sobre esta nueva competencia federal, AuBert, Traité... op. cit., p. 57; y PetitPIERre-SAUVAIN, Environmental Law... op. cit., p. 34. La competencia en materia de aguas de la Confederación se recoge actualmente en el artículo 76CF.
} 
ciada por el Consejo Federal para tratar los dos problemas separadamente. El Consejo Federal prometió que resolvería el segundo de ellos en un plazo razonable, lo que, finalmente, sucedió a través de la reforma constitucional aprobada en el referéndum que se llevó a cabo el 1 de abril de 1962, reforma que introducía una nueva competencia federal en el texto de la Constitución ${ }^{27}$. La necesidad de una acción federal en el campo de la energía se puso de manifiesto entre los años 1957 y 1961, a partir del debate generado sobre la iniciativa de reforma de la Constitución rechazada en 1955. Finalmente, la regulación constitucional de la materia se concretó en la disciplina del uso pacífico de la energía nuclear (art. 24quinquies) y el transporte de combustibles (art. 26bis), cuestiones que, por su propia naturaleza, parecían requerir una intervención a nivel fede$\mathrm{ral}^{28}$. En cualquier caso, la introducción de los artículos 24quater, 24quinquies y 26bis mostraba con cierta claridad que el aumento de la preocupación acerca del deterioro del medio ambiente acabaría dando lugar a un incremento de las competencias federales.

En definitiva, pues, la reforma constitucional de 1953 marca el inicio de un período de reformas, que, básicamente, consistirán en la atribución de nuevas competencias a la Confederación, centradas en cuestiones que se refieren a la intervención de los poderes públicos en la ordenación de las relaciones entre los seres humanos y el entorno. Ahora bien, a pesar de que el aumento de la sensibilidad por las cuestiones ambientales tendrá como consecuencia la ampliación de las facultades de la federación, no debe perderse de vista que los cantones obtendrán una responsabilidad significativa en la ejecución, entre otras materias relevantes, de la política de ordenación del territorio, la política energética o la política de protección del medio ambiente, entendida esta última como un título competencial particular y diferenciado a partir de $1971^{29}$. Por lo tanto, el aumento de las tareas a realizar por los poderes públicos como consecuencia de la necesidad de articular respuestas a las nuevas demandas sociales relacionadas con el medio ambiente, aunque, aparentemente, parece referirse, con carácter primordial, a la federación, de hecho, acabará afectando también a los cantones, que pasarán a ser participantes activos en el desarrollo de las políticas que se diseñen en este ámbito y que no dejarán de man-

27 Vid., en relación con estas iniciativas de reforma constitucional de un contenido ambiental incipiente, Roland RUfFIEUX, «Les données de l'histoire constitutionelle», en Alois RIKLIN (ed.), Handbuch Politisches System der Schweiz. 1. Grundlagen / Manuel Système politique de la Suisse. 1. Le contexte, Paul Haupt Berna-Stuttgart, 1983, p. 186.

28 Vid. PetitPierre-Sauvain, Environmental Law... op. cit., p. 34.

29 Vid. Andreas Auer, Giorgio Malinverni y Mcliel Hottelier, Droit constitucionnel suisse. 1. L'État, Staempfli, Berna, 2000, p. 309. 
tener un bagaje competencial amplio, en relación, sobre todo, con la ejecución $^{30}$.

En cualquier caso, debe destacarse que la incorporación a la Constitución federal de normas ambientales o protoambientales (como es el caso del antiguo artículo 24sexties, referido a la protección de la naturaleza y del paisaje) será dificultosa, como pone de manifiesto, sin ir más lejos, la introducción de la disposición citada. Desde 1924, esta materia había formado parte de la agenda del Parlamento federal. Sin embargo, la asunción por parte de la Confederación de competencias en este terreno había despertado una fuerte oposición en los cantones. Finalmente, el 27 de mayo de 1962, después de que las organizaciones conservacionistas efectuaran una fuerte presión en tal sentido, un referéndum acabó por introducir en la Constitución federal una nueva disposición que otorgaba competencias a la Confederación sobre la materia ${ }^{31}$. Esta reforma constitucional constituiría, según PETITPIERRE, un ensayo para una aproximación global a las cuestiones relativas a la protección del medio ambiente y debe ponerse en relación con la atribución de competencias energéticas a la Confederación en el período correspondiente al final de la década de los cincuenta y al inicio de la siguiente ${ }^{32}$.

Sin embargo, las dificultades en relación con el desarrollo de una política ambiental federal no terminan con la reforma constitucional en que se atribuye la competencia para realizarla. Una vez asignada a la Confederación la competencia mediante la reforma constitucional correspondiente, la puesta en marcha de políticas públicas y la elaboración de normas federales no es un proceso rápido. Por seguir con el ejemplo del artículo 24 sexties, una vez introducida en la Constitución la nueva competencia federal después del referéndum de 1962, el Consejo Federal tuvo que negociar durante cuatro años para llevar adelante una ley sobre la materia $^{33}$. En cualquier caso, la Ley federal de protección de la naturaleza y el

\footnotetext{
${ }^{30}$ Sobre el desarrollo del Derecho ambiental constitucional a nivel federal y sobre el lugar que les corresponde a los cantones en la realización de la política ambiental, vid. Helene KeLLER, Umwelt und Verfassung. Eine Darstellung des kantonalen Umweltverfassungsrechts, Schultess, Zúrich, 1993, p. 5 y ss.

31 Vid. Roland RufFIeUX, «Les données...» op. cit., p. 193. En relación con este título competencial, que se recoge actualmente en el artículo $78 \mathrm{CF}$, debe tenerse en cuenta la existencia del Parque Nacional Suizo. Sobre el mencionado espacio natural protegido, vid., en particular, PETITPIERRESAUVAIN, Environmental Law... op. cit., p. 130.

32 Vid. PetitPierre-Sauvain, Environmental Law... op. cit., p. 34.

${ }^{33} \mathrm{Ibid}$. El procedimiento legislativo suizo tiene una fase previa, el llamado procedimiento de consulta, en que las iniciativas parlamentarias son negociadas con los actores afectados para conseguir
} 
paisaje de 1966 tiene una historia comparable, por su génesis dificultosa y lenta, a la Ley de protección del medio ambiente de 1984, a la que nos referiremos más adelante. En definitiva, debemos apuntar en este punto que los problemas planteados entre los distintos poderes públicos a la hora de llevar a cabo políticas ambientales no finalizan, como ilustra el caso del artículo 24sexties, con la reforma de la Constitución y la clarificación del régimen competencial. En cualquier caso, antes de pasar a referimos al artículo 24septies, debemos consignar que, en 1969, la Constitución federal fue reformada de nuevo para atribuir a la Confederación una competencia, limitada a la fijación de principios, en materia de ordenación del territorio ${ }^{34}$.

El proceso de introducción de nuevas disposiciones en la Constitución federal relativas a sectores vinculados a la protección del medio ambiente a lo largo de los años cincuenta y sesenta culminaría con el artículo 24 septies. Con la inclusión de esta disposición en la antigua Constitución, se hace posible la elaboración de una ley federal general sobre la protección del medio ambiente. Así, después de la reforma constitucional de 1971, se nombró una comisión, presidida por el profesor Leo SCHÜRRNANN, que presentó un anteproyecto de una Ley de protección del medio ambiente en 1973. Sin embargo, el procedimiento de consulta sobre el texto de la comisión que se abrió en el año siguiente no halló el consenso esperado. A consecuencia de ello, los trabajos quedaron parados hasta que el Consejo Federal presentó un informe, acompañado de un nuevo proyecto de ley elaborado por un grupo de trabajo bajo la dirección del profesor Thomas FleINER, a principio de la década de los ochenta. Sin embargo, la Ley de protección del medio ambiente (en adelante, LPMA), que desarrollaba el contenido del artículo 24septies, no se aprobó hasta 1984 y no entró en vigor hasta el 1 de enero de $1985^{35}$.

El Derecho ambiental a nivel federal, a partir de la entrada en vigor del artículo 24septies y, sobre todo, a partir de la LPMA, se ha desarrollado de manera particularmente intensa. Después de su conformación inicial durante las décadas de los setenta y los ochenta, en los últimos años, el

que, cuando se lleven a cabo, cuenten con un respaldo amplio. La búsqueda del consenso que caracteriza, en general, a todas las políticas federales convierte la lentitud en algo inherente al sistema, más allá de que se trate del ejercicio de competencias relacionadas con el medio ambiente o no.

${ }^{34}$ Ibid.

${ }^{35}$ Para el proceso de elaboración de la LPMA, vid. Wagner PFEIFER, Umweltrecht... op . cit , p. 21. En general, sobre el contenido de la Ley, vid. Patrizia MACCHIA, Normativa a tutela dell'ambiente e disciplina del sistema produttivo nell'ordimmento giuridico elvetico, Jovene, Nápoles, 1994, p. 54 y ss. 
Derecho ambiental suizo ha ampliado su contenido de manera relevante ${ }^{36}$. El fundamento para el nuevo impulso que ha recibido el desarrollo del Derecho ambiental en Suiza en tiempos recientes se encuentra, en primer lugar, en el hecho de que el proceso de deterioro ambiental no se ha detenido, circunstancia que, de hecho, es habitual en la gran mayoría de estados. Además, deben tenerse en cuenta, en relación con los cambios sustanciales en el Derecho ambiental suizo de los últimos años, el impacto de los más recientes desarrollos tecnológicos, las modificaciones en las condiciones marco internacionales así como los defectos que se han apreciado en la legislación a la hora de su aplicación ${ }^{37}$. Además, debe tenerse en cuenta la transferencia de nuevas competencias de trascendencia ambiental a la Federación. Esto es lo que ha sucedido en materia de energía, ya que, hasta 1990, a pesar de las reformas constitucionales que dieron lugar a los artículos 24quinquies y 26bis, a las que ya nos hemos referido, el grueso de la política energética era aún competencia cantonal ${ }^{38}$. Así pues, puede hablarse de una fase de profunda renovación del Derecho ambiental que aún parece no haberse cerrado.

Esta fase de renovación encuentra su punto culminante en el tratamiento que el medio ambiente recibe en el nuevo texto constitucional. La reforma total de la Constitución aprobada por el pueblo y los cantones en 1999 ha introducido algunos cambios significativos en la materia que nos ocupa y ha incidido, particularmente, en el sistema de distribución de competen$\operatorname{cias}^{39}$. Entre las novedades más relevantes, más allá de las cuestiones competenciales, hemos de destacar la incorporación al texto constitucional de concepto de desarrollo sostenible, incorporación que parece responder a las tendencias más recientes del constitucionalismo en relación con la protección del medio ambiente ${ }^{40}$. Sin embargo, Luzius MADER sostiene que,

\footnotetext{
36 Vid. KARLEN, «Neues Umweltrecht...» op. cit., p. 44.

37 Vid. op. cit., p. 39.

38 Vid. Petitpierre-Sauvain, Environmental Law... op. cit., p. 34.

39 Una perspectiva general sobre la distribución de competencias en materia de medio ambiente en la nueva Constitución en Luzius MADER, «Die Umwelt in neuer Verfassung? Anmerkungen zu umweltschutzrelevanten Bestimmungen der neuen Bundesverfassung», en Umweltrecht in der Praxis / Le Droit de l'environnement dans la pratique, 2000, p. 111 y ss.
}

40 Sobre la recepción del concepto de desarrollo sostenible en la nueva Constitución federal, vid. Damel Jositsch, «Das Konzept der nachhaltigen Entwicklung (Sustainable Development) im Völkerrecht und seine innerstaatliche Umweltsetzung», en Umweltrecht in der Praxis / Le Droit de l'environnement dans la pratique, 1997, p. 119 y ss. Entre las constituciones más recientes que incorporan la noción de desarrollo sostenible, debe destacarse la Constitución polaca de 1997, que menciona entre los fines del Estado que se enumeran en el artículo 5, la protección del medio ambiente de acuerdo con los principios del desarrollo sostenible. 
contrariamente a lo que sucedía con otras formulaciones planteadas antes de la aprobación del nuevo texto constitucional, como, por ejemplo, las que proponían Alfred KöLz y Jörg Paul MÜLleR, la Constitución de 1999 no apunta especialmente a las demandas ecológicas ${ }^{41}$. A pesar de ello, no puede dejar de apreciarse que estas demandas han recibido mayor atención en la Constitución actual en comparación que la que les prestaba el texto anterior, incluyendo las modificaciones parciales más recientes ${ }^{42}$. Sea como sea, el artículo dedicado a la protección del medio ambiente en el nuevo texto, se corresponde esencialmente con el antiguo artículo $24 \mathrm{sep}$ $t_{i e s}{ }^{43}$, aunque hay que tener en cuenta que, a diferencia de éste, el nuevo artículo 74CF renuncia a la mención particularizada de campos de actuación prioritarios. Atendiendo a la posibilidad de nuevos peligros para el medio ambiente ${ }^{44}$ así como a la aparición de nuevas áreas problemáticas en el futuro, se preve reaccionar a través de una actualización constante del catálogo de prioridades, en lugar de establecerlas con carácter definitivo en el texto de la Constitución ${ }^{45}$. En cuanto al nuevo artículo 75, correspondiente a la ordenación del territorio y el urbanismo, debe decirse que tampoco se aleja demasiado del antiguo 22 quater $^{46}$. Finalmente, no puede olvidarse en este punto que también las constituciones cantonales han prestado atención a la protección del medio ambiente, de modo que puede considerarse que completan el ordenamiento ambiental a nivel constitucional, complementando el contenido de la Constitución federal ${ }^{47}$.

\section{LA COMPETENCIA FEDERAL EN MATERIA DE PROTECCIÓN DEL MEDIO AMBIENTE}

En el sistema suizo, la distribución final de competencias entre la federación y los cantones se concreta en la Constitución federal ${ }^{48}$. Ésta expli-

41 Vid. MADER, «Die Umweit in neuecr Verfassung?...» op. cit., p. 106.

42 Vid. op. cit., p. 107.

43 Vid. op. cit., p. 111.

44 El informe del Consejo Federal que acompañaba al proyecto de Constitución mencionaba los problemas de los gases causantes del efecto invernadero y los que contribuyen a la destrucción de la capa de ozono, como explica Wagner PFEIFER, Umweltrecht... op. cit., p. 22.

45 Ibid.

46 Vid. MADER, «Die Umwelt in neuer Verfassung?...» op. cit., p. 111.

47 Sobre el desarrollo de la atención por la protección del medio ambiente en las constituciones cantonales, vid. KELLER, Umwelt und Verfassung... op. cit., p. 29 y ss.

$48 \mathrm{Vid}$., en relación con esto, AUBERT, Traité... op. cit., p. 229 y ss. 
cita cuáles son las competencias de la Confederación, de modo que, en base a la cláusula residual del artículo $3 \mathrm{CF}$, aquellas materias que no le han sido atribuidas en la Constitución, permanecen en el acervo competencial de los cantones, como es común en los sistemas federales clásicos. Por lo tanto, la distribución competencial que opera la Constitución es completa, sin necesidad de ninguna norma suplementaria, como sería el caso español, donde ello se articula a través del llamado Bloque de Constitucionalidad, cuyo contenido es mucho más amplio que el de la Constitución formal ${ }^{49}$. En este sentido, pues, la interpretación que se haga del artículo 74CF determinará hasta dónde puede llegar la Confederación en materia de protección del medio ambiente, de modo que aquellas atribuciones que no deriven de ésta u otra disposiciones de la Constitución federal quedarán en manos de los cantones. Debe notarse, sin embargo, que el sistema tiene un punto de fuga, ya que las leyes federales no están sometidas al control de constitucionalidad por cuanto son vinculantes para todos los órganos jurisdiccionales y, particularmente, para el Tribunal Federal (art. 191CF). Por otra parte, hay que tener en cuenta que, de acuerdo con el artículo 49.1CF, el Derecho federal prevalece sobre el cantonal, de modo que, en el caso que existan una norma cantonal y una norma federal referidas a la misma materia, la última deja sin eficacia a la primera (Bundesrecht bricht kantonales Recht) ${ }^{50}$. Esto quiere decir, básicamente, que, en el caso que la Confederación, mediante una ley, vaya más allá de los límites competenciales que le marca la Constitución, no hay manera de controlar esta infracción de la Constitución y, de hecho, la ley citada deja sin eficacia al Derecho cantonal que se le oponga, aun si éste es respetuoso con la distribución competencial constitucional. Sin embargo, de la posibilidad que esto se produzca, no debería extraerse la

\footnotetext{
49 Sobre la falta de lagunas (Lückenlosigkeit) en el sistema de distribución de competencias en base al reparto que hace la Constitución federal, vid. Peter WIDMER, Normkonkurrenz und Kompetenzkonkurrenz im schweizerischen Bundesstaatsrecht (Die Bundestreue als Schranke der kantonalen Kompetenzausübung), Schulthess, Zúrich, 1966, p. 3 y ss.

${ }^{50}$ Sobre la fuerza derogatoria del Derecho federal después de la entrada en vigor de la Constitución de 1999, vid. Peter ForSTER, «Eigenständigkeit der Kantone, Vorrang und Einhaltung des Bundesrechts und Bundesgarantien», en Fleiner, Forster, Misic y Thalmann, Die neue schweizerische Bundesverfassung... op. cit., p. 134. Sobre el funcionamiento de la fuerza derogatoria del Derecho federal como instrumento fundamental en la resolución de problemas competenciales, vid. Widmer, Normkonkurrenz und Kompetenzkonkurrenz... op. cit., p. 9 y ss. El principio Bundesrecht bricht kantonales Recht tiene una larga historia en el ámbito germánico. Para una análisis sobre su génesis y su evolución, así como para una interpretación de su contenido, vid. Marcel BRIDEL, Précis de droit constitutionnel et public suisse (I), Payot, Lausana, 1965, p. 187 y ss.; Max Imboden, «Die staatsrechtliche Bedeutung des Grundsatzes "Bundesrecht bricht kantonales Recht"» [1942], en Staat und Recht, Helbing \& Lichtenhahn, Basilea-Stuttgart, 1971, pp. 129-143; y Walther BURCKHARDT, «Eidgenössisches Recht bricht kantonales Recht» [1927], en Aufsätze und Vorträge 1910-1938, Stämpfli, Berna, 1970, pp. 205-218.
} 
conclusión de que es lo habitual. De hecho, los complejos equilibrios que determinan la toma de decisiones a nivel federal, sobre los cuales no podemos extendemos aquí, hacen de esta posibilidad algo extraño a la cultura política suiza.

La competencia federal en materia de protección del medio ambiente derivada del artículo 74CF debe completarse con lo que disponen una constelación de preceptos constitucionales que atribuyen competencias a la Confederación en campos conexos con el medio ambiente. En este contexto, debemos referirnos al artículo $75 \mathrm{CF}$, que atribuye a la Confederación la competencia para legislar sobre los principios que han de regir la normativa sobre la ordenación del territorio y el urbanismo; el artículo $76 \mathrm{CF}$, relativo a las aguas, incluyendo la normativa referente a las construcciones destinadas a regular su curso y a la utilización de la energía hidroeléctrica; el artículo 77CF, relativo a la legislación de montes; el artículo 78CF, referido a la protección de la naturaleza y el patrimonio cultural; el artículo 79CE relativo a la caza y la pesca; así como también el artículo $80 \mathrm{CF}$, relativo a la protección de los animales. Por otra parte, deben considerarse también los artículos 84 (protección de los Alpes), 85 y $86 \mathrm{CF}$ (impuestos de circulación), así como el resto de disposiciones relativas al tráfico. En este mismo contexto, debe hacerse notar que los artículos del 89 al 91CF establecen el nuevo régimen constitucional de la energía, que incluye aspectos relativos al transporte y la tributación. Además, deben citarse también las competencias de la Confederación en materia de agricultura (104CF), vivienda (art. 108CF), salud (art. 118CF) así como en materia de ingeniería genética (arts. 119 y $120 \mathrm{CF})^{51}$.

\subsection{La determinación de la noción de medio ambiente en tanto que objeto de la competencia federal recogida en el artículo $74 \mathrm{CF}$}

Dejando a parte las competencias conexas a la protección del medio ambiente que acabamos de mencionar, intentaremos delimitar a partir de ahora el contenido de la materia medio ambiente en cuanto a objeto de la competencia atribuida al legislador federal en el artículo 74CE La determinación de la materia ambiental no es una cuestión simple, pero, en todo caso, es clave para decidir que poder público está investido de la compe-

\footnotetext{
${ }^{51}$ Sobre todo este conjunto de disposiciones y su relación con el Derecho ambiental, vid. WAGNER PFEIFER, Umweltrecht... op. cit., p. 22.
} 
tencia. En este punto, puede hablarse, básicamente, de dos tendencias en la literatura científica en relación con la delimitación del medio ambiente. Aunque debe reconocerse que, en relación con esto, se dan muchos matices, corrientemente, suele distinguirse entre las concepciones amplias o extensivas y las concepciones estrictas o restringidas a la hora de clasificar las aproximaciones que se han hecho a la noción jurídica de medio ambiente en el seno de la doctrina. En este sentido, debemos partir del dato que la Constitución federal parece adoptar una aproximación más bien restrictiva sobre lo que cabe entender por medio ambiente en tanto que materia sobre la que se proyecta una competencia legislativa por parte de la Confederación. Sin embargo, como veremos, esta primera percepción sobre la solución constitucional no está libre de problemas.

\subsubsection{La solución constitucional a la determinación del contenido del medio ambiente como materia competencial: el medio ambiente natural}

Para el lector no familiarizado con las sutilezas del debate sobre el concepto jurídico de medio ambiente, parece que la noción se remite, más bien, a un objeto global cuyos contornos son más bien imprecisos. Esta visión intuitiva da lugar a una de las tendencias hermenéuticas que se han desarrollado a la hora de determinar el contenido de la noción jurídica de medio ambiente. Se trata de las llamadas aproximaciones extensivas $^{52}$. Este tipo de interpretaciones pretenden abarcar bajo el manto del concepto de medio ambiente todo el entorno natural y artificial del hombre a través de una perspectiva global. Naturalmente, hay múltiples matices en relación con las diversas formulaciones que pueden englobarse en esta clase. Partiremos, en cualquier caso, de la concepción más amplia, para ilustrar de qué tipo de perspectiva estamos hablando. Diremos, entonces, que, para las formulaciones más extremas entre las interpretaciones extensivas del concepto, el medio ambiente sería el conjunto de la realidad que determina el entorno global de un cierto sujeto. En el caso del hombre, de acuerdo con esto, sería característico el medio ambiente se constituyera en dos áreas: la socio-económica y la natural.

La concepción amplia o extensiva de medio ambiente incluiría, pues, en su formulación más extrema, no sólo el medio ambiente natural, sino

\footnotetext{
${ }^{52}$ La utilización de la expresión «extensivo» para el tipo de interpretaciones a que nos referimos es bastante común. Vid., por todos, KelLer, a Umwelt und Verfassung... op. cit., p. 105.
} 
también factores sociales y económicos ${ }^{53}$. Esta delimitación amplísima ha tenido un cierto éxito en el terreno de la sociología, de modo que, entre algunos especialistas de esta disciplina, se han incluido en el concepto de medio ambiente las condiciones sociales, culturales y políticas que determinan la exterioridad humana ${ }^{54}$. Es obvio que una noción tal, como dice Yves Nicole, «englobe (...) pratiquement tout» ${ }^{55}$. A pesar de ello, esta aproximación particularmente amplia al medio ambiente ha sido recibida en el ámbito del discurso jurídico en Estados Unidos en relación con la legislación de impacto ambiental. Así, la National Environmental Policy Act (NEPA), exige un análisis de los impactos de las actividades sujetas a evaluación en el medio ambiente humano (human environment) ${ }^{56}$. En consecuencia, conjuntamente con el medio ambiente natural, se tienen en cuenta también las consecuencias de las actividades evaluadas en el entorno socio-económico. La protección del medio ambiente consiste, pues, en este contexto, no sólo en la determinación y salvaguarda de las condiciones de vida naturales, sino también en la protección ante los perjuicios sociales o económicos ${ }^{57}$. Ahora bien, si se configura el medio ambiente en tanto que objeto de un título competencial de una manera tan amplia, se tiende a configurar una competencia global ${ }^{58}$. Es en este punto dónde topamos con el problema esencial que deriva de la interpretación mencionada del concepto de medio ambiente.

Debe reconocerse, sin embargo, que esta configuración particularmente extensa del objeto medio ambiente no parece encontrar demasiado eco en Europa y, particularmente, en Suiza. De hecho, a pesar de que, aparentemente, una concepción tal amplifica las posibilidades tuitivas, debe admitirse que, incluso en el terreno de la evaluación de impacto ambiental, que una noción tan amplia toma una dimensión tan considerable que exige la intervención de una multitud de especialistas de los campos más variados que acaban convirtiendo el procedimiento de evaluación en algo

53 Vid., en este sentido, Nicole, L'étude d'impact... op. cit., p. 42.

${ }^{54}$ Vid. KelLer, Umwelt und Verfassung... op. cit., p. 106.

55 Vid. Nicole, L'étude d'impact... op. cit., p. 42. Sirva para ilustrar este comentario la aproximación de la autora española Paz Vizcaíno Sánchez-Rodrigo, para quién, en Introducción al Derecho del Medio Ambiente, CTO Medicina, Madrid, 1996, p. 5, el medio ambiente es «nuestro entorno y todo lo que en él se encuentra, TODO lo que nos rodea» (las mayúsculas son de la misma autora).

56 Vid. Nicole, L'étude d'impact... op. cit., p. 42.

57 Vid. Wilfried ERBGuth, Rechissystematische Grundfragen des Umweltrechts, Duncker \& Humblot, Berlín, 1987, p. 45.

58 Vid. op. cit., p. 46. 
muy costoso y lento, aparte de dar lugar a dificultades metodológicas a veces insuperables ${ }^{59}$. En este sentido, en Suiza, los tribunales han considerado que los impactos sociales y económicos no han de ser tomados en cuenta dentro del procedimiento de evaluación de impacto ambiental, si no se encuentran en relación con un cambio en el medio ambiente físico ${ }^{60}$. Debe reconocerse, pues, que la adopción del concepto de medio ambiente adoptado en la legislación de impacto ambiental norteamericana puede despertar perplejidad y, desde luego, no parece haya cosechado mucho éxito en Suiza.

Sin embargo, parece que, por el contrario, sí que ha tenido una cierta difusión en Europa una noción de medio ambiente emparentada con la anterior. Se trata de la conceptualización del medio ambiente como el entorno físico global, es decir, excluyendo las condiciones culturales, económicas o sociales. Se trata de una restricción sobre las nociones de mayor amplitud en cuanto al contenido, pero, sin embargo, puede considerarse una concepción extensiva con relación a las aproximaciones que prefieren acotar el concepto al entorno natural. Así, de acuerdo con este tipo de aproximaciones, el medio ambiente sería no sólo el entorno natural del ser humano, esto es, la biosfera (medio ambiente primario), sino también el entorno autocreado, la tecnosfera (medio ambiente secundario), esto es, por ejemplo, las zonas de vivienda o las redes de circulación ${ }^{61}$.

Sin embargo, este tipo de nociones también han suscitado objeciones. La fundamental es aquella que parte de la finalidad ecológica de la protección del medio ambiente. De acuerdo con esto, se trataría, pues, de fijar las condiciones de vida del ser humano (y, eventualmente, por conexión, de otras especies) desde una perspectiva estrictamente biológica. Así, autores como Wilfried ERBGUTH denuncian que la protección de las formas de vida en un sentido biológico se disuelve cuando se considera en el marco de una paleta relativamente amplia de intereses socio-económicos que pueden llegar a dar lugar una cierta confusión ${ }^{62}$. Esta crítica, sin embargo, parece más apropiada para las concepciones de medio ambiente en el sentido más amplio (como la de la NEPA), ya que, en definitiva,

\footnotetext{
59 Vid. Nicole, L'étude d'impact... op. cit., p. 42.

60 Vid. op. cit., p. 43.

61 Vid. Otfried HöFFE, «Umweltschutz ais Staatsaufgabe - Umrisse einer rechtsphilosophischen Begründung», a VVAA, L'homme dans son environnement / Mensch und Umwelt, Éditions Universitaires, Friburgo, 1980, p. 311.
}

62 Vid. ERBguth, Rechtssystematische Grundfragen... op. cit., p. 46 y 47. 
no debe perderse de vista que las condiciones de vida del ser humano parece que superan lo estrictamente biológico y el entorno protegido debe responder necesidades que van más allá de la pura y simple supervivencia para llegar a alcanzar un cierto bienestar, no pudiéndose dejar de lado aquí la vinculación de la protección del medio ambiente con la dignidad de la persona ${ }^{63}$. Más efectiva parece la objeción, sobre todo desde un punto de vista que aquí nos ocupa, que consiste en poner de manifiesto la dificultad de definir un ámbito de actuación diferenciado que permita su formulación como título competencial dada una configuración del medio ambiente tan amplia. Esto puede dar lugar, en definitiva, a que el poder público a quién se ha atribuido la competencia relativa a la protección del medio ambiente se halle habilitado para intervenir en prácticamente cualquier campo.

Teniendo en cuenta, pues, los problemas derivados de las concepciones extensivas, concepciones que, por otra parte, parece que encuentran su fundamento en el sentido habitual de la expresión «medio ambiente» (o de sus equivalentes en otras lenguas), una parte de los que se han ocupado de la cuestión han intentado precisar y delimitar de manera más restringida el contenido del medio ambiente en el ámbito del discurso jurídi$\mathrm{co}^{64}$. Lo que se pretende, en definitiva, cuando se intenta restringir el sentido de la expresión «medio ambiente» (o sus equivalentes) para su uso en discurso jurídico es hacerla manejable, ya que se considera, por lo general, que el carácter global de las concepciones extensivas acaba privándolas de sentido y convirtiéndolas en inaplicables ${ }^{65}$. El paradigma del tipo de aproximación restrictiva al concepto de medio ambiente es, en la doctrina centroeuropea, aquella que tiende a identificar medio ambiente y medio ambiente natural (natürliche Umwelt) ${ }^{66}$. Las aproximaciones de este tipo son adoptadas por una cantidad relevante de autores, así como, en muchas ocasiones por el mismo legislador o por los tribunales en los diversos ordenamientos jurídicos del Occidente europeo. En cuanto a Suiza, debe constatarse que, de hecho, la aproximación digamos naturalista ha sido asumida de manera mayoritaria. Como nota Helene KELLER,

${ }^{63}$ Vid., particularmente, Benoît JoRION, «La dignité de la personne humaine ou la difficile insertion d'une règle morale dans le droit positif», a Revue de Droit Public, 1999, n. ${ }^{\circ}$ 1, p. 223 . En la doctrina española, Eduardo Javier RUIZ VIEYTEZ, a El derecho al ambiente como derecho de participación, Ararteko, s/d, p. 29, ha puesto de manifiesto esta vinculación, del mismo modo Remedios SánCHEZ Ferriz, en el prólogo a Francisco Antón BARberÁ y Juan Ignacio Soler Tormo, Policía y medio ambiente, Comares, Granada, 1996, p. XIX.

${ }^{64}$ Vid. KeLLeR, Umwelt und Verfassung... op. cit., p. 106.

${ }^{65}$ Ibid.

${ }^{66} \mathrm{Ibid}$. 
con una cierta sorpresa, consecuencia de los problemas que este tipo de aproximaciones plantea, como veremos seguidamente, el legislador y el constituyente (tanto federal, como, en general, cantonal) han adoptado justamente esta perspectiva ${ }^{67}$. La consecuencia más evidente de ello es la asunción por parte de la Constitución federal del término «medio ambiente natural» en su artículo $74^{68}$. Con ello, parece que la norma fundamental excluye las interpretaciones extensivas y opta, de manera clara, por una aproximación restrictiva al concepto de medio ambiente.

\subsubsection{Los problemas que plantea la noción de medio ambiente natural}

Aunque, aparentemente, la noción de medio ambiente natural pueda parecer relativamente clara, el caso es que, de hecho, las concepciones llamadas restrictivas acostumbrar a diverger sobre qué es lo que debe entenderse por tal, de modo que el resultado no es precisamente un consenso doctrinal sobre el contenido del concepto. Para poner de manifiesto el tipo de problema a que nos referimos nos fijaremos en dos autores que se han mostrado partidarios de una noción restrictiva de medio ambiente para el discurso jurídico. Dominik KoEchlin, en una monografía dedicada al principio de precaución (Vorsorgeprinzip), considera que lo que debe entenderse por medio ambiente es el mundo natural que nos rodea, lo que, según él, incluye, los animales y las plantas, el aire, el agua y el suelo, elementos todos ellos que considera necesarios para la vida ${ }^{69}$. Por supuesto, no se incluye en un concepto de medio ambiente entendido de este modo el medio ambiente artificial o transformado por el ser humano, en particular, las construcciones de cualquier tipo, de acuerdo con las características propias de la noción restrictiva de medio ambiente ${ }^{70}$. Luzius MADER, por su parte, en un trabajo dedicado al medio ambiente en la nueva Constitución federal, tiene otra opinión sobre lo que debe incluirse en el concepto de medio ambiente, de modo que su aproximación acaba resultando más compleja que la de KoEChLin. Para MADER, el medio ambiente abarca, como en el caso de KoECHLIN, los animales y las plantas (así como

\footnotetext{
67 Vid. op. cit., p. 108.

${ }^{6}$ «Natürliche Umwelt», en la versión alemana; «milieu naturel», en la versión francesa; «ambiente naturale», en la versión italiana.

69 Vid. Dominik Koechlin, Das Vorsorgeprinzip im Umweltschutzgesetz unter besonderer Berücksichtigung der Emissions- und Immissionsgrenzwerte, Helbing \& Lichtenhahn, Basilea-Frankfurt am Main, 1989, p. 1.

70 Ibid.
} 
las formaciones a que dan lugar en conjunto, las Lebensgemeinschaften), el aire, el clima, el suelo y el agua, pero, además, incluye aquello que el llama espacios vitales (Lebensräume), en tanto que sistemas en que los elementos anteriores entran en relación ${ }^{71}$.

No pretendemos ser, en este punto, sistemáticos y detallados con el fin de llegar a ofrecer una perspectiva global sobre las distintas delimitaciones que, en la literatura jurídica suiza, se han intentando en relación con la noción de medio ambiente natural. Nos interesa solamente mostrar el tipo de divergencia a que da lugar una aproximación aparentemente sencilla al problema de la determinación del contenido del concepto de medio ambiente. En realidad, se puede ofrecer una gran cantidad de ejemplos en relación con aproximaciones que coinciden en el fondo (el medio ambiente como medio ambiente natural), pero que discrepan en el contenido concreto del mencionado medio ambiente natural. En definitiva, como pone de manifiesto Thomas FLEINER, la noción de medio natural puede ser comprendida tanto de un modo muy amplio como de un modo muy restingido $^{72}$. Por lo tanto, la adopción, por parte de la Constitución federal, de la noción de medio ambiente natural en el artículo 74 no acaba de resolver los problemas que presenta la determinación del alcance material de competencia federal en este ámbito.

Consideremos, pues, una sistematización de las distintas interpretaciones a que puede dar lugar la noción de medio ambiente natural. Si aceptamos que las posiciones restrictivas a las que nos estamos refiriendo son reconducibles a lo que Ottfried HöFfE llama el entorno natural ecológicamente determinado (ökologisch bestimmte natürliche Umgebung $)^{73}$, que, de hecho, puede hacerse coincidir con lo que, habitualmente, llamarnos biosfera, nos puede servir la clasificación que hace este autor para ver el tipo de diferencias que pueden presentarse a la hora de interpretar la noción de medio ambiente natural. Según HöFFE, hay cuatro significados posibles diferentes para el concepto de medio ambiente que aquí consideramos. En su sentido más amplio, deberíamos incluir el conjunto de la biosfera, esto es, el aire, el agua, las riquezas del subsuelo, las plantas y los animales. A pesar de esto, frecuentemente, se dejan de lado las materias primas y se incluyen, en un concepto de

\footnotetext{
71 Vid. MADER, «Die Umwelt in neuer Verfassung?...» op. cit., p. 107.

72 Vid. Thomas FleINER, «Art. 24 ${ }^{\text {septies } » ~[1989], ~ a ~ C o m m e n t a i r e ~ d e ~ l a ~ C o n s t i t u t i o n ~ f e ́ d e ́ r a l e ~ d e ~ l a ~}$ Conféderation suisse II, Helbing \& Lichtenhahn-Schultess-Stämpfli, Basilea-Zúrich-Berna (versión francesa, a partir del original alemán, de C. Pilloud), p. 5.
}

73 Vid. HöFFE, «Umweltschutz als Staatsaufgabe...» op. cit., p. 312. 
medio ambiente en sentido amplio, ya sólo el aire, el agua, el suelo, las plantas y los animales, como es el caso consignado más arriba de Dominik KoECHLIN. En un sentido aún más estricto, no tendríamos en cuenta las plantas y los animales. Finalmente, en el sentido más estricto, se entendería que sólo el aire y, en tanto que se propaga por él, el ruido forman parte del Medio ambiente ${ }^{74}$. por supuesto, a las concepciones distintas de lo que cabe entender por medio ambiente corresponden modelos de protección asimismo distintos ${ }^{75}$. Sin embargo, lo que nos interesa destacar fundamentalmente es que dan lugar a diferentes delimitaciones del campo de actuación de los poderes públicos que tienen asignada una competencia en la materia.

Además de los problemas que presenta la delimitación concreta de la noción de medio ambiente natural, que no es tan clara como, aparentemente, pudiere haber parecido, debería tenerse en cuenta a la hora de valorar su utilidad los problemas que genera desde el punto de vista del diseño de la actividad tuitiva de los poderes públicos. En realidad, una atención cuidadosa a las implicaciones de la expresión hace equívoca y ambigua la equivalencia entre «medio ambiente», «medio ambiente natural» (natürliche Umwelt) y «medio ambiente natural del ser humano» (natürliche Umwelt des Menschen $)^{76}$. La naturaleza equívoca de la restricción se nos muestra a la hora de determinar el alcance de lo que queremos decir con la expresión «natural». Supongamos que nos referimos, con esta noción, a aquello que podría caracterizarse como espacios o zonas donde el ser humano no interviene, descartando, pues, el medio ambiente humano, es decir aquellos espacios donde el ser humano ha transformado su entorno de manera significativa, de modo que, de entrada, desaparece claramente cualquier posible referencia a factores socio-económicos o culturales.

Sin embargo, como pone de manifiesto Susanne SPRÖSSER, esto plantea una serie de interrogantes. En particular, ¿significa esto la exclusión de la noción de medio ambiente natural los ecosistemas que, desde hace siglos son explotados por los hombres y, precisamente a través de esto han obtenido un carácter peculiar? ¿Debe conservarse para siempre el estado en que nos llega el entorno sin permitir modificaciones? ¿El medio ambiente protegido por el Derecho es el medio ambiente dado, sea cual sea su estado? O, por el contrario, ¿hay intervenciones que deben permitirse?

\footnotetext{
${ }^{74}$ Ibid.

75 Ibid.

${ }^{76}$ En este sentido, vid. KelLeR, Umwelt und Verfassung... op. cit., p. 108.
} 
Incluso, quizá, ¿habrá intervenciones necesarias? ${ }^{77}$. Se trata de cuestiones complicadas que deben aclararse y que, en todo caso, expresan la dificultad que plantea considerar como objeto de protección el medio ambiente natural. Consideremos, en particular, la paradójica exclusión del medio ambiente modificado por el ser humano que podría comportar una restricción del medio ambiente al medio ambiente natural. Si nos planteamos esto, nos damos cuenta rápidamente que no parece que pueda restringirse la protección del medio ambiente a los lugares que permanecen en un estado digamos que original (Urzustand), porque, de entrada, hay bien pocos que lo estén, en el caso que eso sea posible ${ }^{78}$.

Por decirlo con las palabras del biólogo Ramon FolCH, que difícilmente podríamos mejorar para expresar lo que queremos, «(...) pensar que hem de respectar l'ambient, entenent per tal les àrees encara més o menys intactes com a garantia del nostre futur és cometre dos errors alhora Primer, és no adonar-se que aquestes àrees intactes o no existeixen de cap manera o representen apenes el 10\% de la superficie de la Terra, o sigui que no pot ser que d'aquest modest $10 \%$ en depengui el futur del $90 \%$ restant $i$ que no és assenyat concentrar els millors esforços a respectar aquest espai residual, perquè això seria una excel lent manera de desviar la profunda realitat de les coses. El segon error és pensar que la transformació antròpica de la realitat és necessàriament negativi, de manera que transformat equivalgui a deteriorat: en termes d'interessos humans, la transformació feta d'acord amb uns determinats principis no solament no és negativa, sinó que és l'única cosa positiva que podem imaginar Així que, del que en realitat es tracta és de construir un ambient acollidor $i$ ecologicament sostenible» ${ }^{79}$.

\footnotetext{
77 Vid. Susanne SpRÖSSER, Was ist das Ziel der Umweltpolitik, Rüeger, Grüsch, 1989, p. 1.

78 Vid., en aquest sentit, ZelLer, Umwelt und Verfassung... op. cit., p. 108.

79 Vid. Ramon FolCH, «Socioecologia i governabilitat: la subversió postindustrial», en Rafael Grasa y Andreu Ulied (eds.), Medi ambient i governabilitat a la Mediterrània, Institut Català de la Mediterrània d'Estudis i Cooperació, Barcelona, 1997, p. 36. En el mismo sentido, Joandomè-nec Ros, en «El uso y disfrute de los espacios protegidos y de interés: política forestal y de parques naturales. La protección de la biodiversidad dentro de una estrategia de desarrollo sostenible» en Juan Grau Rahola y Josep EnRic Llebot (coords.), Política ambiental y desarrollo sostenible, Instituto de Ecología y Mercado, Madrid, 1999, p. 226, afirma lo siguiente: «Las áreas protegidas no pueden consistir en islas de protección, pequeñas y aisladas, en medio del mar de explotación, abandono o degradación del resto del territorio. Se sabe desde hace algunos decenios que existe una relación directa entre el tamaño de un área natural determinada y el número de especies que puede contener; su biodiversidad. Una reserva natural pequeña (y en España y Europa todas lo son, porque el territorio está muy ocupado históricamente por la población, y fragmentado en un mosaico de saltus, ager, urbs, a los que desde hace un siglo se ha añadido industria) y aislada (sin conexión con otras áreas protegidas más o menos cercanas, por ejemplo, a través de bosques de ribera fluviales,
} 
De hecho, la misma normativa, en tanto acaba refiriéndose a cuestiones como el ruido o los residuos, en realidad, lo que hace es disciplinar el medio ambiente altamente modificado de las concentraciones urbanas y reconducirlo hacia una adaptación al bienestar humano. Esto implica cuestionarse la adecuación del término «natural» para calificar el medio ambiente protegido $\mathrm{y}$, en definitiva, en este contexto, parece más razonable la solución de la Constitución española, cuando habla de un «medio ambiente adecuado para el desarrollo de la persona». Así pues, ni por contenido ni por finalidad, parece que la noción de medio ambiente natural se adapte a las necesidades que plantea la protección del medio ambiente, incluso en aquellos casos como el suizo en que ha sido adoptada de manera literal por el propio ordenamiento jurídico. El hecho es que, en realidad, la mayoría de las aproximaciones que se presentan como concreciones de la noción de medio ambiente natural, en realidad, acaban abarcando la totalidad del espacio físico. Así, una concepción restrictiva del medio ambiente no puede obviar que el objeto de tutela debe incluir también los sectores del espacio global modificados por el ser humano, ya que, en definitiva, el medio ambiente se protege para proteger al mismo ser humano ${ }^{80}$. Se trata, en definitiva, de proteger no sólo los natürlichen Lebensgrundlagen, los fundamentos naturales de la vida, sino también la calidad de vida en los espacios habitados ${ }^{81}$. Debe concluirse aquí que, en realidad la noción de medio ambiente natural no elimina el carácter global que el concepto de medio ambiente parece reclamar $\mathrm{y}$, sin embargo, a través de la restricción que opera, plantea más problemas de los que resuelve. Parece que, a pesar de todo, nos vemos obligados a considerar el medio ambiente protegido como el espacio físico global configurado de modo que permite el desarrollo de la vida de las personas. Por tanto, de nuevo, nos hallamos ante el problema de cómo configurar esto como una materia competencial.

o de los bosquetes que delimitan las áreas de cultivo; es decir, sin corredores biológicos) está destinada a la degradación y banalización de la biota».

${ }^{80}$ En este sentido, Thomas FLEINER, en «La legislazione in materia di protezione dell'ambiente», en Tecnica e diritto nell'ambito della protezione dell'ambiente. Atti della giornata di studio del 29 de maggio 1990, Comissione ticinese per la formazione permanente dei giuristi, Lugano, 1991 (versión italiana de Pierluigi Pasi a partir del original alemán), p. 14, pone de manifiesto que, en cualquier caso, el artículo 24 septies de la antigua Constitución federal era una norma encaminada a proteger al ser humano, lo que, por supuesto, puede predicarse del actual artículo 74CR La conclusión de adoptar este punto de vista antropocéntrico en el tema que nos ocupa es casi inmediata: debe tenerse en cuenta no sólo el medio ambiente natural, sino también aquél que ha sido modificado por el hombre a la hora de establecer el ámbito de protección, como destaca ERBGUTH, en Rechssystematische Grudfragen..., p. 45.

${ }^{81}$ Así lo pone de manifiesto KeLLER, en Umwelt und Verfassung... op. cit., p. 109. La autora considera, incluso, preeminente (vorrangig) la defensa de la calidad de vida a la protección de los natürlichen Lebensgrundlagen, aunque esto, para nosotros, ya no es tan claro. 


\subsubsection{El medio ambiente como materia transversal}

Por todo lo dicho hasta ahora, independientemente de que adoptemos una concepción restrictiva o no, el medio ambiente se configura como un objeto jurídico global que, por otra parte, define el ámbito material de una competencia concreta. Por supuesto, esto plantea dificultades graves a la hora de concretar cuál es el alcance material del título competencial en cuestión. Si aceptarnos que, una competencia es una facultad de actuar sobre un objeto o materia determinados ${ }^{82}$, debemos preguntamos, entonces, sobre cómo puede delimitarse el medio ambiente. El hecho de que exista una competencia legislativa específica (atribuida a la federación) sobre la materia hace surgir la pregunta de si se trata, efectivamente, de una competencia horizontal, esto es, si, en definitiva, dado el carácter global del objeto, se trata de una competencia que penetra en los títulos competenciales particulares y, en consecuencia, condiciona su ejercicio.

Ésta es la conclusión a la que llegaba Thomas FLEINER en su comentario al antiguo artículo 24septies de la Constitución federal. Aplicando su razonamiento al actual artículo $74 \mathrm{CF}$, debería concluirse que la atribución de una competencia legislativa a la federación en este ámbito se solapa, por la naturaleza del objeto, a todas las competencias federales existentes. Por lo tanto, en resumen, de acuerdo con esto, la competencia que se reconoce a la Confederación se configuraría como una competencia horizontal, de la que, en función de la formulación constitucional en tanto que mandato-atribución, a la que haremos referencia en el siguiente apartado, se derivaría la obligación de combatir los daños contra el medio ambiente en tanto que objeto global ${ }^{83}$. Por lo tanto, el mandato-atribución constitucional del artículo $74 \mathrm{CF}$ acabaría afectando a muchas otras tareas

82 Vid., en este sentido, Ignacio María de LoJENDIO E IRURE, «El modelo autonómico de la Constitución de 1978», en VVAA, Primeras Jornadas de Estudio del Estatuto de Autonomía del País Vasco I, Instituto Vasco de Estudios de Administración Pública / Herri-Arduralaritzaren Eusko IkasErakuntza, Oñati, 1983, p. 41. Sobre el concepto de competencia, vid., asimismo, Enrique ÁlvAREZ Conde, Curso de Derecho Constitucional (II), Tecnos, Madrid, 1997 (2ª edición), p. 423 y ss.; Jorge de Esteban y Pedro J. González Trevijano, Curso de Derecho Constitucional Español (III), Madrid, 1994, p. 846; Enric FoSSAS, «El repartiment de competèricies: nocions básiques», en BARCEló y Vintró, Dret Públic de Catalunya op. cit., p. 181 y ss.; Joaquim Tornos I MAS, «Les competéncies de la Generalitat», en Enoch Albertí, Eliseo AJA, Tomás Font, Xavier PAdrós y Joaquim Tornos, Manual de Dret Públic de Catalunya, Marcial Pons-Institut d'Estudis Autonòmics, Barcelona-Madrid, 2002 ( $3^{\text {a }}$ edición), p. 184 y ss.; y Jaume VerNet I LlOBET, «L'autonomia, i les competéncies de la Generalitat», en Miquel Caminal Badia y Jordi Matas Dalmases (eds.), El sistema polític de Catalunya, Edicions Universitat de Barcelona-Tecnos-Servei de Publicacions de la Universitat Autònoma de Barcelona, Barcelona, 1998, p. 243.

83 Vid. Fleiner, «Art. 24 septies $_{\text {op. }}$ cit., p. 15. En el mismo sentido, vid. també NiCOLE, L'étude d'impat... op. cit., p. 88. 
constitucionales y exigiría una implementación coordinada de las diferentes políticas sectoriales en un proceso de optimización constante ${ }^{84}$. En este sentido, Kuttler hace notar que la finalidad de protección global que deriva del artículo 74CF no sólo determina el ejercicio de otras competencias federales, como hace notar Thomas FLEINER ${ }^{85}$, sino que, de hecho, penetraría en todas las competencias federales existentes y, más allá de esto, afectaría también, en algún sentido, al ejercicio de las competencias cantonales ${ }^{86}$.

Así, Astrid EPINEY, Hanspeter PfenNiger y Reto Gruber, en un trabajo colectivo, han entendido que, en tanto que la competencia atribuida a la federación en materia de protección del medio ambiente es una competencia transversal (Querschnittkompetenz), la federación puede penetrar en todas las áreas sectoriales cuando sea necesario para garantizar la realización efectiva del encargo constitucional. Además, por el hecho de que esta competencia esté atribuida a la Confederación, los cantones no dispondrían de ninguna competencia normativa propia en la materia, de modo que sus posibilidades en este terreno, dependerían, en última instancia de la legislación federal ${ }^{87}$. Así pues, la competencia en materia de medio ambiente atribuida a la federación acabaría presentando una tendencia remarcable hacia la expansión horizontal que incidiría, claramente, en las competencias cantonales ${ }^{88}$.

Llegados a este punto, nos vemos enfrentados a los problemas de delimitación respecto a las competencias sectoriales que presenta un título competencial tan amplio. La opción de la Constitución federal suiza (así como la de la Constitución española) de atribuir una competencia genérica en materia de protección del medio ambiente presenta, pues, el peligro

\footnotetext{
84 Vid. Wagner Pfeifer, Umweltrecht... op. cit., p. 22.

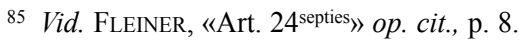

86 Vid. KUTTLER, «Umweltschutz und Raumplanung» op. cit., p. 3.

87 Vid. Astrid EPINEY, Hanspeter PfEnNIGER y Reto GRUBER, Europäisches Umweltrecht und die Schweiz. Neuere Entwicklungen und ihre Implikationen, Stämpfli, Berna, 1999, p. 55. Sobre la fuerza expansiva de la competencia en materia de protección del medio ambiente, vid., en relación con España, EscobAR RocA, La ordenación constitucional... op. cit., p. 155. Sin embargo, debe notarse que, entre España y Suiza existe una diferencia determinante en el tratamiento constitucional de la cuestión. En Suiza, la obligación de proteger el medio ambiente y la atribución de un título competencial a la federación para ello se resuelven de forma conjunta, mientras que, en España, esto se hace en dos preceptos distintos (artículos 45 y 149.1.23CE).

${ }^{88}$ En relación con la capacidad de expansión horizontal del título competencial en materia de medio ambiente, vid. Antonio EMBID IRUJO, «El rol del Estado: ¿vigilante o gestor?», en Juan GRAU RAHOLA y Josep EnRIC LleBot (coords.), Política ambiental y desarrollo sostenible, Instituto de Ecología y Mercado, Madrid, 1999, p. 318.
} 
de permitir la expansión incontrolada del ámbito de actuación de uno de los actores del sistema en ejercicio de una competencia que difícilmente puede encontrar unas fronteras definidas. Parecería preferible, aparentemente, tanto para evitar el desequilibrio del sistema de atribución de competencias como en aras a una mayor claridad, la configuración de una norma vinculante para todos los poderes públicos, del tipo del artículo $45 \mathrm{CE}$, sin necesidad de recoger un título competencial específico de carácter sustantivo para una materia que, por su misma naturaleza, es difícilmente delimitable ${ }^{89}$. En este sentido, Luciano PAREJo Alfonso, en base justamente a su capacidad de penetración en todas la políticas públicas sectoriales, se ha referido a la imposibilidad de definir claramente un título competencial en materia de protección del medio ambiente ${ }^{90}$.

Una competencia transversal configurada en unos términos tan amplios puede dar lugar a un vaciamiento competencial de los entes a los que no ha sido atribuida. Dada la existencia de un título competencial en esta materia, sin embargo, más allá de las propuestas de lege ferenda, debe intentarse una solución interpretativa que logre afrontar con éxito el peligro de expansión indefinida del título competencial en materia de protección del medio ambiente. Una solución que se ha considerado por una parte de la doctrina española es la configuración de la materia, referida como una materia residual ${ }^{91}$. De acuerdo con esto, serían objeto de la competencia en materia de protección del medio ambiente todos aquellos ámbitos materiales relacionados con el entorno que no han sido recogidos

\footnotetext{
${ }^{89}$ La Ley Fundamental de Bonn, aunque recoge varias competencias sectoriales relacionadas con la protección del medio ambiente (lo que, por otra parte, también ocurre tanto en el caso de Suiza como en el de España), no hace referencia a ningún título competencial genérico en materia de protección del medio ambiente, conformándose con configurar una obligación de protección de los poderes públicos en el artículo $2^{\circ}$ a GG. Vid., en relación con esto, Luca MezzeTtI, «Constitución del ambiente y protección de la naturaleza en el ordenamiento jurídico alemán», en RuIz-RIco Ruiz, Derecho comparado... op. cit., pp. 80 y 81. Sin embargo, debe notarse, en cualquier caso, la utilidad que puede tener un título competencial en materia de protección del medio ambiente que no tenga una dimensión sustantiva transversal, pero, en cambio, tenga una dimensión formal transversal, esto es, la capacidad de diseñar los instrumentos generales de tutela del medio ambiente que superan el ámbito de las competencias sectoriales, como puede ser la evaluación de impacto ambiental o los sistemas de prevención y control de la contaminación.

90 Vid. Luciano PAREJo Alfonso, «Ordenación del territorio y medio ambiente» en DDAA, I Congreso Nacional de Derecho Ambiental. Ponencias, Sevilla, 1995, p. 127.

${ }^{91}$ Esta solución ya la propuso, al poco de la entrada en vigor de la Constitución, Santiago MuÑoz MACHADO, en su trabajo «La distribución de competencias entre el Estado, las comunidades autónomas y las corporaciones locales en materia de medio ambiente», en Documentación Administrativa, n. ${ }^{\circ}$ 190, abril-junio 1981, p. 366. En el mismo sentido, María Jesús MONTORo CHINER, «Residuos sólidos», en José EsteVE PARDO, Derecho del medio ambiente y administración local, Civitas, Madrid, 1996, p. 171; y, RuIZ VIEYTEZ, en [El derecho... op. cit.], pp. 102 y 103.
} 
en un título competencial sectorial específico. Sin embargo, si bien es verdad que esta configuración del título competencial en materia de protección del medio ambiente tiene una cierta plausibilidad en el sistema constitucional español, es insostenible en el caso de Suiza, ya que, en cualquier caso, son las competencias recogidas en la Constitución federal las que deben definirse de manera positiva (y, por tanto, no hay opción a delimitarlas como residuales), ya que aquello que no está recogido en la Constitución federal como competencia de la Confederación es, automáticamente, competencia cantonal. En definitiva, los cantones no tienen atribuidos, títulos competenciales de manera expresa, sino que tienen compentencia en todo aquello que la Constitución federal no atribuye a la federación. Así, el hecho de que las competencias cantonales, de acuerdo con el artículo $3 \mathrm{CF}$, se definan de manera negativa, impide considerar la competencia del artículo 74CF como una competencia residual, si no es con relación al resto de las competencias federales, lo que, en todo caso, tiene más bien poca utilidad.

De hecho, en Suiza, se interpreta unánimemente la competencia atribuida a la Confederación por el artículo 74CF como una facultad de intervención amplia que funciona horizontalmente y que, por lo tanto, le permite, a la hora de cumplir con el mandato para cuya realización ha sido atribuida, intervenir normativamente de manera particularmente amplia para proteger el medio ambiente. Como consecuencia de esta interpretación, puede concluirse que la protección del medio ambiente favorece las tendencias centralizadoras, justificadas, aparentemente, por la finalidad de buscar una racionalización en la materia ${ }^{92}$. A pesar de ello, sin embargo, en el caso de Suiza, debemos remarcar que un conjunto de normas no escritas y de usos políticos en el funcionamiento de las instituciones federales, aparte de su misma estructura interna e, incluso, de su propia composición, hacen difícilmente imaginable que la Confederación utilice este título competencial tan ampliamente configurado para vaciar, de modo torticero, las competencias de los cantones ${ }^{93}$.

\footnotetext{
92 Éste sería, por ejemplo, el caso de Italia, compone de manifiesto Luca MezzetTI, a «La protección jurídica del ambiente en el Derecho comparado: Alemania, Italia, Francia y Gran Bretaña», en Gerardo Ruiz-Rico Ruiz (coord.), La protección del medio ambiente en el ordenamiento jurídico español, Universidad de Jaén, Jaén, 1995, p. 37 y ss.

93 Vid. Croisat, Le fédéralisme... op. cit., pp. 45 y 46. Particularmente, en relación con esto, debe tenerse en cuenta la existencia del procedimiento de consulta en la elaboración de una parte importante de la legislación federal, lo que permite una intervención activa de los cantones durante el proceso. Sobre el procedimiento de consulta, vid. Hanna MuRAlt MüLLER, «Vernehmnlassungsverfahren - helvetisches Ritual oder modernes partizipatorisches Instrument der Konkordanzdemokratie», en Gesetzgebung heute / Législatión d'ajourd'hui / Legislazione oggi / Legislaziun dad oz (LeGes), 1997/2, pp. 17-39.
} 
En consecuencia, debemos concluir que el título competencial recogido en el artículo $74 \mathrm{CF}$ abarca prácticamente cualquier intervención normativa destinada a realizar el mandato de protección que incorpora. En definitiva, pues, el ámbito material de la competencia federal en materia de protección del medio ambiente acaba definiéndose en base a criterios de finalidad, que, en última instancia, permite definir lo que, de otro modo, sería difícilmente delimitable ${ }^{94}$. Éste no obsta, sin embargo, para que la competencia se defina, desde un punto de vista material, de manera particularmente amplia, en tanto que incorpora una capacidad de penetración profunda en los ámbitos competenciales sectoriales.

\subsection{El artículo 74CF como mandato al legislador federal y sus consecuencias en la definición funcional del título competencial en materia de protección del medio ambiente}

Una vez establecido el ámbito material de la competencia federal en relación con la protección del medio ambiente en base a criterios de finalidad, pasaremos a considerar el título competencial referido desde el punto de vista funcional, esto es, nos fijaremos en las atribuciones que incorpora el artículo $74 \mathrm{CF}$ sobre la materia ya definida ${ }^{95}$. El artículo 24 septies de la antigua Constitución federal fue considerado por sus comentaristas y, particularmente, por Thomas Fleiner, como algo más que una simple norma de atribución de competencias a al Confederación, a saber, como un auténtico mandato para el legislador federal, que, por lo tanto, no sólo podía legislar (porque disponía de la competencia), sino que tenía que hacerlo porque la Constitución así se lo exigía ${ }^{96}$. Por lo tanto, contrariamente a otras disposiciones constitucionales, el 24septies obligaba a la Confederación a legislar, a proteger activamente el medio ambiente a través de su actividad legislativa en uso de la competencia que le atribuía la Constitución ${ }^{97}$. El artículo 74 de la nueva Constitución federal no ha alterado la situación. En consecuencia, en este aspecto, todo lo que se ha podido decir sobre el antiguo artículo 24 septies no ha perdido vigen-

\footnotetext{
94 Vid. ERBGUth, Rechtssystematische Grundfragen... op. cit., p. 57.

${ }^{95}$ La competencia integra el sujeto (es decir, el titular; en este caso, la Confederación), el objeto (a saber la materia sobre la que se ejerce la competencia, que es aquello de lo que nos acabamos de ocupar) y la función (o sea, la potestad jurídica de actuación que se ha atribuido). Vid. VERNET I LLOBET, «L'autonomia...» op. cit., pp. 243 y 244.
}

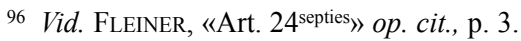

${ }^{97}$ Vid. op. cit., p. 6. 
cia, en tanto que el carácter doble de la norma constitucional, como facultad y como obligación se conserva plenamente. Según Thomas FLEINER, que, como hemos visto, dirigió el grupo de trabajo que elaboró el anteproyecto de la IPMA, el artículo 24septies contenía un mandato a largo plazo para realizar una protección ambiental eficiente ${ }^{98}$. El primer destinatario del mandato era el legislador federal ${ }^{99}$. Así pues, éste no sólo se configura como titular de una competencia, sino como destinatario de un mandato para cuyo cumplimiento la competencia ha sido atribuida.

La federación, por lo tanto, queda investida, según la mencionada norma constitucional, de una facultad de legislar, de aprobar, por consiguiente, normas generales referentes a la protección del medio ambiente ${ }^{100}$. Debemos planteamos, sin embargo, hasta dónde puede llegar esta facultad de legislar en cumplimiento del mandato constitucional o, dicho de otro modo, si el legislador federal puede abarcar toda la normación correspondiente a la materia, es decir, si, de acuerdo con la configuración constitucional del título competencial, a los cantones les queda algún tipo de atribución normativa en este ámbito o no. De entrada, debemos constatar que, contrariamente a lo que sucede con la ordenación del territorio, donde la Constitución otorga a la federación una competencia para dictar principios, en el caso de la protección del medio ambiente, la Constitución habla de legislar sin ninguna restricción aparente ${ }^{101}$. Por lo tanto, cabe entender que, en esta materia, el ámbito competencial funcional asignado a la Confederación es mayor que en el terreno conexo de la ordenación del territorio, donde los cantones, en base a las restricciones con que se formula la competencia federal en la Constitución, disponen de un mayor margen. El artículo $74 \mathrm{CF}$, pues, atribuye a la Confederación una facultad-obligación, en principio, irrestricta, de legislar. A partir de la legislación federal que se dicte en cumplimiento de dicha facultad-obligación, se concretarán las facultades que queden en manos de los cantones y las que sean asumidas por la Confederación. En este sentido, debe notarse que el desarrollo reglamentario de la LPMA dependerá, en principio, del Consejo Federal, en particular, en relación con los reglamentos que completan la ley, para cuya aprobación está expresamente habilitado por la propia LPMA, y en referencia también a los reglamentos de ejecución destinados a concre-

\footnotetext{
98 Vid. FLEINER, «La legislazione...», p. 12.

99 Vid. op. cit., p. 13.

100 En cuanto a la competencia federal en esta materia como competencia legislativa, vid. NiCOLE, L'étude d'impact.. op. cit., p. 85.
}

101 Vid. FleINER, «Art $24^{\text {septies }_{》}}$ op. cit., p. 13. 
tar las obligaciones legales y a definir, por ejemplo, con mayor precisión ciertas nociones $^{102}$.

Según Thomas FleINER, la obligación de legislar que deriva del artículo 74CF puede ser concretada a través de varios tipos de normas. De esta manera, las disposiciones en materia de protección del medio ambiente, pueden revestir la forma de leyes federales, de decretos federales de alcance general $\mathrm{o}$, simplemente, de reglamentos ${ }^{103}$. El legislador podrá normar en este ámbito con una cierta libertad atendiendo, en todo caso, a la finalidad tuitiva que le impone la Constitución. Para hacerlo, en principio, podrá utilizar cualquier tipo de norma y, en tanto que lo haga, demarcará al mismo tiempo el ámbito que queda para que los cantones ejerzan algún tipo de competencia normativa en este terreno. De hecho, la noción de norma que utiliza en el artículo 74CF es suficientemente amplia como para permitir su aplicación a instrumentos de soft law como las que se prevén en el artículo 6.1LPMA ${ }^{104}$. En consecuencia, la federación dispondrá de una amplia competencia normativa en el ámbito de la protección del medio ambiente, que, de hecho, puede permitirle, incluso, la realización de actos de ejecución ${ }^{105}$, aunque, en todo caso, esto dependerá de la reserva de competencia a favor de las instituciones federales que se haya realizado a través de una ley formal ${ }^{106}$. En consecuencia, la federación sólo podría demarcar su ámbito competencial final, en relación con el cumplimiento del mandato del artículo 74CF, a través de una ley federal y no a través de una ordenanza del Consejo Federal, fuente normativa que, en cualquier caso, está sujeta, contrariamente a lo que sucede con la ley federal, al control del Tribunal Federal.

Por lo tanto, obviamente, el cumplimiento por parte del legislador federal con el mandato que deriva del artículo $74 \mathrm{CF}$ es lo que acaba definiendo, negativamente, el ámbito competencial de los cantones. Además, sin embargo, la legislación federal en esta materia tiene otras consecuencias. Así, el Derecho ambiental federal incide, de manera general, en la interpretación de la Constitución, por ejemplo, en relación con la protección

\footnotetext{
102 Vid. Nicole, L'étude d'impact... op. cit., p. 104. En cuanto a la concreción de las disposiciones relativamente ambiguas de la LPMA a través de los reglamentos federales, vid. EPINEY, PFENNIGER y GRUBER, Europäisches Umweltrecht und die Schweiz... op. cit., p. 57.

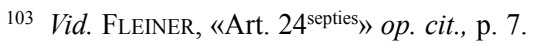

104 Vid. op. cit., p. 8.

105 Vid. Thomas FLEINER, «Umweltschutz- und Raumplanungsrecht», en VVAA, L'homme dans son environnement / Mensch und Umwelt, Éditions Universitaires, Friburgo, 1980, p. 113.

106 Vid. Nicole, L'étude d'impact... op. cit., p. 87.
} 
de la propiedad (art. 26CF) o de la libertad de empresa (art. 27CF), así como en la del Derecho infraconstitucional, así, en el terreno del Derecho privado de inmisiones o en el Derecho relativo a la responsabilidad extracontractual ${ }^{107}$. En cualquier caso, el artículo $74 \mathrm{CF}$ se formula como un mandato-atribución al legislador federal que no parece que comporte el reconocimiento de ningún derecho constitucional individual para los ciudadanos. Aun así, hay quién se cuestiona la existencia, derivada de la propia Constitución, de un derecho tal, que, en cualquier caso, presentaría los consabidos problemas relativos a la titularidad y a su exigibilidad, entre otros. Asimismo, hay quien habla de una finalidad del Estado (Staatsziel) $\mathrm{y}$, en consecuencia, excluye una dimensión subjetiva en la disposición constitucional. Pensamos, con Wagner PFEuEP, que el eventual reconocimiento a algún tipo de derecho individual en relación con la protección del medio ambiente es muy problemática en el caso suizo ${ }^{108}$.

De hecho, el mandato de legislar que deriva de la Constitución no es una obligación que pueda ser exigida por nadie ante un Tribunal ${ }^{109}$. Así, parece claro, de acuerdo con esto, que el mandato constitucional tantas veces citado no contiene ningún auténtico derecho fundamental individual en materia de protección del medio ambiente que pueda ser alegado directamente por los particulares. El destinatario primario del artículo $74 \mathrm{CF}$, como antes del artículo 24septies, es el legislador federal ${ }^{110}$. Sin embargo, el hecho de que no se trate de un mandato exigible ante los Tribunales y que no se reconozca ningún derecho individual no convierte inmediatamente el artículo $74 \mathrm{CF}$ en una simple declaración programática. En este sentido, debemos concluir que este mandato constitucional tiene, al fin y al cabo, una función de catalizador, aunque únicamente sea a través de la técnica de la interpretación conforme a la Constitución en la aplicación de

\footnotetext{
107 Vid. Wagner Pfeifer, Umweltrecht... op. cit., p. 22.

108 Vid. op. cit., p. 23.

109 Vid. FleINER, «Art. 24 $4^{\text {septies}}$ op. cit., p. 7. En consecuencia, la norma mencionada no sería subsumible dentro de la categoría de encargo al legislador, equivalente a la noción alemana de Verfassungsauftrag. Sobre esto, vid. José Julio FERNÁNDEZ RodRÍGUEZ, La inconstitucionalidad por omisión. Teoría general. Derecho comparado. El caso español, Civitas, Madrid, 1998, p. 146 y ss. En la doctrina española, también se ha usado para referirse a esta institución la expresión «mandato al legislador». Así, por ejemplo, en Francisco RuBio LloRENTE, «La Constitución como fuente de Derecho» [1979], en La forma del poder (Estudios sobre la Constitución), Centro de Estudios Constitucionales, Madrid, 1993, pp. 95 y 96. En conclusión, no se trataría, pues, de una norma justiciable, en el sentido que nadie puede reclamar al legislador federal que cumpla con la obligación que la Constitución le atribuye.

110 Vid. FleINER, «Art. $24^{\text {septies }}$ op. cit., p. 7. Por supuesto, Fleiner se refiere al antiguo texto, pero lo que dice es plenamente aplicable al actual. En el mismo sentido, vid. MACCHIA, Normativa a tutela dell'ambiente... op. cit., p. 36.
} 
la ley ${ }^{111}$. Aun así, debe concluirse que, a pesar del carácter obligatorio del artículo $74 \mathrm{CF}$, el legislador federal dispone de un vasto poder de apreciación cuando se trata de concretar los términos del mandato ${ }^{112}$. Desde el punto de vista competencial, esto significa que, en realidad, la federación dispone de un margen muy amplio de intervención en la materia.

\section{LA COMPETENCIA NORMATIVA DE LOS CANTONES EN MATERIA DE MEDIO AMBIENTE}

Sea cual sea el alcance de la competencia federal, aunque, en todo caso, parece que éste es bastante amplio, la protección del medio ambiente no se configura sólo como una responsabilidad de la Confederación, sino también de los cantones y las comunas, tal y como pone de manifiesto, particularmente, Otfried HöFFE ${ }^{113}$. De hecho, como hace notar el autor austríaco Peter Bußjäger, es difícil que la complejidad de los problemas ambientales pueda ser enfocada sólo a través de regulaciones uniformes emanadas desde el poder central. Según este autor, una protección del medio ambiente integral exigiría, en todo caso la intervención de los entes subcentrales ${ }^{114}$. De entrada, debe decirse que, en realidad, a pesar de los términos amplios en que, como ya hemos visto, se formula la competencia federal del artículo 74CF, esto no excluye la posibilidad de una competencia normativa de los cantones.

En relación con esta cuestión, debemos partir del funcionamiento general del sistema federal en Suiza. En este sentido, a pesar de que una competencia esté atribuida a la federación por la Constitución, los cantones podrán legislar en el ámbito demarcado por dicha competencia siempre que la Confederación no lo haga ${ }^{115}$. Cuando la federación interviene, en virtud del principio Bundesrecht bricht kantonales Recht, la normativa cantonal deviene inválida en aquello en que se oponga a la normativa federal. Un ejemplo relativamente reciente de esto es el hecho de que, a partir de la modificación de la LPMA y de la introducción del actual artículo 65.2, los cantones ya no pueden aprobar ninguna nueva disposición en materia de organismos peligrosos para el medio

\footnotetext{
111 Vid. FleINER, «Art. 24 ${ }^{\text {septies }} »$ op. cit., p. 7.

112 Vid. op. cit., p. 8.

113 Vid. HöFFE, «Umweltschutz als Staatsaufgabe...» op. cit., p. 325.

114 Vid. BUßJÄGER, Die Naturschutzkompetenzen... op. cit., p. 128.

115 Vid. Wagner Pfeifer, Umweltrecht... op. cit., p. 23.
} 
ambiente, ya que, de acuerdo con la ley, este sector queda completamente en manos de la Confederación, cuando antes se había dejado un cierto margen a los cantones ${ }^{116}$.

La LPMA no agota la materia la materia ambiental, sino que es una norma que define el marco general en este terreno. Para la normativa de desarrollo de la ley, el mecanismo de funcionamiento es el mismo que determina el sistema en general. Así, las disposiciones de la LPMA necesitadas de una ulterior concreción abren un espacio que, hasta el momento en que se elaboren reglamentos federales de desarrollo, puede ser colmado por los cantones ${ }^{117}$. Por otra parte, debe reconocerse que, como hemos dicho, la LPMA no cubre todos los aspectos relevantes desde el punto de vista de la protección del medio ambiente. Así, allí donde la LPMA no haya entrado, se abre una posibilidad de intervención normativa por parte de los cantones ${ }^{118}$. En consecuencia, los cantones, como vemos, están investidos de una competencia subsidiaria y pueden legislar en los ámbitos que deje libres el legislador federal ${ }^{119}$.

Sin embargo, a pesar de que, efectivamente, existe, como vemos, un cierto margen par la legislación cantonal ${ }^{120}$, debe constatarse, sin embargo, que debido a la prolija actividad reglamentaria del Consejo Federal, los Parlamentos cantonales no sólo verán delimitado su margen de actuación por la LPMA, sino por los reglamentos federales existentes en la materia ${ }^{121}$. En este sentido, debe notarse que, finalmente, la legislación cantonal en materia de protección del medio ambiente acaba siendo muy restringida en sus perspectivas y, mayormente, acaba limitándose a la adaptación del Derecho federal a las condiciones locales ${ }^{122}$. De todos modos, allí donde la regulación federal es muy sucinta, los cantones tienen un margen más amplio de maniobra. Así, por ejemplo, este margen ha sido aprovechado por la Ley de

\footnotetext{
116 Vid. Jürg Hofer, «Bedeutung, Handlungsbedarf und Perspektiven der USG-Revision für die Kantone», en Umweltrechtr in der Praxis /Le Droit de l'environnement dans la pratique, 1996, p. 558.

117 Vid. Wagner PfeIfER, Umweltrecht... op. cit., p. 23.

118 Ibid.

119 Por todos, vid. Keller, Umwelt und Verfassung... op. cit., p. 122. Así ocurre también en sistemas similares a Suiza, como es el caso de Austria, donde los Länder no sólo ejecutan la legislación federal, sino que también elaboran una normativa propia. En relación con ello, vid. MAYER y SCHMELz, «Environmental Law in Austria ... » op. cit., p. 31.

${ }^{120}$ Efectivamente, la normativa federal, en tanto que no se agota la materia, deja un cierto margen para legislar a los cantones. Vid., en este sentido, WAGNER PFEIFER, Umweltrecht... op. cit., p. 23.

121 Así lo pone de manifiesto HOFER, en «Das kantonale Umweltschutzrecht» op. cit., p. 396.

122 Vid. PetitPierre, Environmental Law... op. cit., p. 39.
} 
Protección del Medio Ambiente (Umweltschutzgesetz) del cantón de BaselLandschaft para establecer una normativa adicional más o menos sustancial (particularmente, en relación con la agricultura) ${ }^{123}$.

De acuerdo con lo que venimos diciendo, los cantones pueden, en consecuencia, elaborar una política ambiental propia, ya que, en definitiva, disponen de una competencia normativa residual en la materia ${ }^{124}$. En realidad, como ya sabemos, la Constitución no libera a los cantones de velar por la protección del medio ambiente en el marco de sus atribuciones. No se puede olvidar, además, que, en general, los cantones están obligados a la protección del medio ambiente por sus propias constituciones. En relación con esto, el artículo 65.1LPMA establece que, mientras el Consejo Federal no use sus facultades para aprobar reglamentos, los cantones podrán dictar sus propias disposiciones en el marco de la ley. De este modo, la competencia normativa de los cantones abarcará todo aquel ámbito que, efectivamente, no haya sido ocupado por los reglamentos federales. Esto sí, para ejercer estas facultades normativas residuales, deberán informar al Departamento Federal de Interior ${ }^{125}$.

En definitiva, pues, existe una competencia normativa residual en materia ambiental en manos de los cantones, que, en particular, por medio de sus parlamentos, podrán elaborar disposiciones normativas para proteger el medio ambiente siempre que no se contradigan con las normas federales $^{126}$. De hecho, en 1989, poco después de la aprobación de la LPMA, Jean-François EGLI y Robert ZIMMERMANN podían afirmar que la ley federal no había reemplazado a las disposiciones cantonales en materia de protección del medio ambiente, en la medida en que éstas conservaban un alcance propio más allá de su relación con el Derecho federal ${ }^{127}$. No parece que la situación haya cambiado, aunque debe cobrarse conciencia de la amplitud que ha ido adquiriendo el Derecho ambiental federal y, por lo tanto, del poco margen que les va quedando a los cantones ${ }^{128}$. Sea como

\footnotetext{
123 Vid. HofER, «Das kantonale Umweltschutzrecht» op. cit., p. 411.

124 Vid. Nicole, L'étude d'impact... op. cit., p. 98.

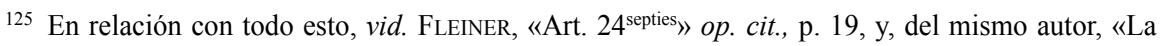
legislazione... »op. cit., p. 26.

126 Vid. PetitPierre, Environmental Law... op. cit., p. 39.

127 Vid. Jean-François EgLi y Robert ZimmERMANN, «Premières expériences judiciaires en matière de législation fédérale sur la protection de l'environnement», en Baurecht / Droit de la Construction, . $^{\circ} 3,1989$, p. 57.

${ }^{128}$ Sobre las disposiciones cantonales dentro del campo de aplicación de la LPMA y los efectos de su entrada en vigor en la legislación cantonal, vid. Nicole, L'étude d'impact... op. cit., p. 99 y ss.
} 
sea, como defienden EPINEY, PfENNIGER y GRUBER, los cantones no disfrutarían de una competencia normativa propia en materia de medio ambiente, sino que sus atribuciones se definirían de manera negativa, en función del ejercicio que la federación haga de su propia competencia, aunque, eso sí, les quedaría, en todo caso la ejecución (de acuerdo con el artículo 65.1LPMA) ${ }^{129}$.

Por lo tanto, debe concluirse que, dentro de un marco limitado, los cantones pueden completar la regulación federal, ejerciendo una cierta competencia normativa en los ámbitos en que la legislación de la Confederación deje un margen para su desarrollo. Por supuesto, la política ambiental cantonal deberá asegurar una aplicación apropiada de la legislación federal y no deberá ser contradictoria con la de los otros cantones ${ }^{130}$. ¿Ahora bien, esta posibilidad de legislar por parte de los cantones es también una obligación? ¿Hasta qué punto los cantones están obligados a elaborar leyes propias en la materia por la Constitución federal? Para responder a esto, debemos constatar, en primer lugar, que las constituciones cantonales más recientes prevén una obligación de este tipo. Aparte, sin embargo, se podría establecer, con carácter general e independientemente de lo que digan las constituciones cantonales, una obligación en este sentido derivada de la misma Constitución federal, aplicable, en todo caso a aquellos cantones que no la hayan introducido en su propia norma fundamental $^{131}$.

Más allá, sin embargo, de la facultad de completar la legislación ambiental federal, de acuerdo con la competencia residual que les viene atribuida por la Constitución federal en su artículo 3, debe consignarse aquí que los cantones tienen un amplio margen de actuación en relación con el medio ambiente de acuerdo con un conjunto de competencias propias que les permiten intervenir en este campo. Así, no puede olvidarse que la Constitución federal asegura a los cantones, en el ámbito de lo que podría llamarse Derecho ambiental funcional, competencias sustanciales. En este contexto, particularmente, deben mencionarse las considerables atribuciones de que disfrutan los cantones en materia de ordenación del territorio y urbanismo, en relación con la protección de la naturaleza y el paisaje o, incluso, en el terreno de la energía ${ }^{132}$. Esto permite a los canto-

\footnotetext{
129 Vid. Epiney Pfenniger y Gruber, Europäisches Umweltrecht und die Schweiz... op. cit., p. 57.

130 Vid. PetitPIERRe, Environmental Law... op. cit., p. 30.

131 Vid. Wagner PFEIFER, Umweltrecht... op. cit., p. 23.

132 Así lo pone de manifiesto KeLLER en Umwelt und Verfassung... op. cit., p. 122. Puede verse una exposición general sobre el Derecho urbanístico y de ordenación del territorio en Suiza, acompañada de una amplia selección bibliográfica, en ScHÜRmANn y HÄNNI, Planungs-, Bau und... op. cit., p. 49 y ss.
} 
nes realizar una política ambiental propia y sustantiva, siempre dentro de los márgenes que delimita la legislación federal emanada en ejercicio de la competencia atribuida por el artículo $74 \mathrm{CF}^{133}$.

De hecho, cuestiones como el ahorro de energía o las políticas de conservación acostumbran a estar reguladas en la legislación cantonal y son implementadas por las propias autoridades cantonales, aunque una nueva ley federal ha ampliado las atribuciones federales en materia energética recientemente ${ }^{134}$. Sin embargo, el ámbito de mayor incidencia de los cantones a través de una competencia conexa con la de medio ambiente es aquél que les abren sus atribuciones en materia urbanística y de ordenación del territorio. En este sector, la mayor parte del Derecho existente es Derecho cantonal ${ }^{135}$. Ni que decir tiene que esto tiene importantes efectos en las posibilidades de los cantones de incidir sobre el medio ambiente. En realidad, la competencia en materia urbanística estaba originariamente en manos de las comunas, pero los cantones fueron absorbiendo progresivamente atribuciones en esta materia, de modo que, actualmente, ejercen la mayor parte de facultades en este campo, con una incidencia remarcable aún del poder local ${ }^{136}$.

Es evidente que la separación constitucional entre una competencia normativa federal en materia de medio ambiente, definida con un carácter particularmente amplio en el artículo 74CF, y una competencia federal a nivel de principios en materia urbanística que deja un margen de actuación muy importante a los cantones de acuerdo con el artículo 75ACF, plantea dificultades. Es inevitable el solapamiento entre ambos títulos competenciales, de modo que, como era de prever, la LPIU, dictada, en principio, en ejercicio de la competencia federal en materia de legislación ambiental, acaba conteniendo disposiciones que inciden claramente en la ordenación del territorio, como el artículo $24^{137}$. A la inversa, los cantones, por medio de algunas de sus actuaciones, pueden condicionar la competencia federal en materia de medio ambiente, siendo todo ello manifestaciones de la transversalidad del objeto.

\footnotetext{
133 Vid. Nicole, L'étude d'impact... op. cit., p. 98.

134 Vid. PetitPierre, Environmental Law... op. cit., p. 39.

135 Vid. SchÜrmann y HÄNNI, Planungs-, Bau und... op. cit., p. 11.

136 Ibid.

137 Sobre los problemas competenciales que plantea esta separación material entre la ordenación del territorio y el medio ambiente en el caso suizo, vid. NiCOLE, L'étude d'impact... op. cit., p. 90 y ss.
} 
Finalmente, en relación con las atribuciones normativas cantonales, debe tenerse en cuenta que los cantones disfrutan de una competencia plena en relación con la regulación de su estructura administrativa y de los procedimientos que ante ella se sustancian ${ }^{138}$. Esto quiere decir que, en la medida en que tengan atribuidas facultades de ejecución en la materia, podrán regular con una cierta libertad los aspectos formales que correspondan. A pesar de ello, sin embargo, debe notarse que, en general, se admite una cierta intervención federal en este terreno de acuerdo con criterios de necesidad, esto es, la intervención de la Confederación será admisible siempre que sea necesaria para la aplicación correcta del Derecho federal, pero sólo en ese caso, aunque debe reconocerse que este criterio es particularmente ambiguo ${ }^{139}$.

\section{LA EJECUCIÓN DE LA POLÍTICA AMBIENTAL}

Como hemos visto, la LPMA constituye el núcleo normativo fundamental de la política ambiental federal y cumple, ni que sea parcialmente, con el mandato de legislar del artículo 74CR De acuerdo con la mencionada ley, se deducen una serie de facultades concretas de desarrollo normativo e, incluso, algunas próximas a la ejecución que son atribuidas a la Administración federal. Deberemos analizar ahora, a partir del marco constitucional, hasta dónde pueden llegar las atribuciones federales en cuanto a la ejecución en materia de medio ambiente, partiendo de la premisa de que, posiblemente, el Derecho ambiental es uno de los sectores normativos donde la ejecución cobra mayor importancia ${ }^{140}$.

Como sabemos, la LPMA concreta las atribuciones de la federación y de los cantones, tanto en lo que afecta a su desarrollo como a su ejecución. Pese a que el antiguo artículo 24septies atribuía la ejecución en materia de medio ambiente a los cantones, con carácter general, se decía que la ley federal podía contemplar excepciones ${ }^{141}$. Esta posibilidad, que no ha sido modificada por el actual artículo 74CF, permite a la federación incidir tanto en el desarrollo normativo de la LPMA como en su ejecución. De

\footnotetext{
138 Vid. NiCOLE, L'élude d'impact... op. cit., p. 106 y ss.

139 Vid. op. cit., p. 107.

140 Vid. FleINER, «Art. $24^{\text {septies }}$ op. cit., p. 21.

141 Vid. WAgner Pfeifer, Umweltrecht... op. cit., pp. 127 y 128, en relación con la competencia ejecutiva de la federación en materia de medio ambiente. Vid. también, en referencia a la misma cuestión, pero apoyándose en el antiguo texto constitucional, NiCOLE, L'étude d'impact... op. cit., p. 85 .
} 
hecho, la dicción de la disposición constitucional ha suscitado críticas entre sus comentaristas y ha dado lugar a una controversia doctrinal en el seno de la doctrina iuspublicista suiza en relación con su alcance exacto ¿De acuerdo con el artículo 74CF, el legislador federal dispone de una especie de atribución en blanco que le permitiría, eventualmente, confiar la totalidad de la ejecución de la legislación ambiental a las autoridades federales (o exclusivamente a las autoridades cantonales)? ¿Debería verse, por el contrario, una prioridad concedida a las cantones, en el sentido de que no pueden ser privados de la ejecución en materia ambiental sin una causa justificada? ${ }^{142}$ En cualquier caso, contrariamente a la mayor parte de los artículos atributivos de competencias en la Constitución federal, el artículo 74CF permite al legislador federal la posibilidad de reservar la ejecución en esta materia a la propia Confederación ${ }^{143}$. De acuerdo con esto, la Administración federal ha asumido, a partir de la LPMA, una parte relevante de la ejecución en relación con la protección del medio ambiente $^{144}$.

¿Qué criterios deben guiar la actuación federal a la hora de la asignación concreta de las tareas de ejecución? Siguiendo a BRUNNER, Yves Nicole propone los siguientes para preferir la ejecución federal: motivos de racionalidad, particularmente cuando la Confederación dispone ya de las estructuras adecuadas para asegurar la ejecución; la exigencia de una aplicación perfectamente uniforme del Derecho federal; el carácter transfronterizo que pueden tener determinadas actuaciones sobre el medio ambiente, tanto si se trata de las fronteras intercantonales como internacionales; la importancia de las dificultades técnicas que puedan, eventualmente, aparecer; y, finalmente, el riesgo de fracaso en la puesta en práctica del Derecho federal, especialmente cuando las autoridades cantonales puedan estar expuestas a fuertes presiones de intereses particulares $^{145}$. Debe reconocerse que la ejecución presupone un know-how técnico e instalaciones adecuadas y que esto, en algunos casos, puede exigir la ejecución a nivel federal. En este sentido, debe tenerse en cuenta la posibilidad de que surjan dificultades de carácter técnico a la hora de la ejecución, ya que los cantones, sobre todo, los menos poblados, pueden encontrarse ante dificultades insuperables para disponer de los

\footnotetext{
142 Vid. NiCOLE, l'étude d'impact... op. cit., p. 86.

143 Vid., en este sentido, FLEINER «Art. $24^{\text {septies }}$ op. cit., p. 20.

144 La asunción de atribuciones ejecutivas en el ámbito de la política ambiental por parte del poder central en los estados compuestos es, de hecho, algo habitual, tal como pone de manifiesto RUIZ VIEYTEZ, en [El derecho... op. cit.], Ararteko, s/d, p. 100.
}

145 Vid. Nicole, L'étude d'impact... op. cit., p. 86. 
conocimientos especializados requeridos, como pone de manifiesto Adrian Vatter en relación con las comunas más pequeñas ${ }^{146}$. Por otra parte, a favor de la ejecución federal, puede aducirse también la neutralidad en relación con las condiciones de la competencia en el merca$\mathrm{do}^{147}$.

Inversamente, entre las razones que pueden aducirse para justificar la ejecución por parte de los cantones, pueden mencionarse las siguientes: la necesidad de un seguimiento en el tiempo de determinadas tareas, lo que parece hacer preferible la Administración más próxima; la existencia de medidas cuya naturaleza está estrechamente ligada a las condiciones particulares del lugar donde deben ser aplicadas; o el hecho de que determinadas tareas de ejecución requieran un contacto intenso con la población $^{148}$. Así, por ejemplo, Thomas FLEINER hace notar la influencia de las particularidades de las condiciones geográficas (tanto en lo que respecta a la geografía física como en lo que se refiere a la geografía humana) en el diseño de las medidas particulares de protección del medio ambiente ${ }^{149}$. Esto, por supuesto, es un factor a favor de dejar la ejecución a la Administración que está en mejores condiciones de responder a estas particularidades.

La conclusión final, en el caso de Suiza, debe partir del hecho que, en principio, cuando una tarea puede ser cumplida de manera igualmente satisfactoria por la federación y por los cantones, la primera debe abstenerse de intervenir en virtud del principio de subsidiariedad ${ }^{150}$. De acuerdo con esto, hay, en el fondo, una preferencia por la ejecución cantonal que convierte la intervención federal en excepción. Ésta es la solución de la propia LPMA. Así, aunque el Consejo Federal juega un papel determinante en la protección del medio ambiente, de acuerdo con el carácter de federalismo de ejecución que se predica del sistema suizo, la LPMA establece que la responsabilidad de la ejecución de la ley federal es, con carácter general de los cantones ${ }^{151}$. Así, de acuerdo con los artículos 36 y 41LPMA, existe un principio general a favor de la eje-

\footnotetext{
146 Vid. Adrian VATTER, «Föderaler Politikvollzug am Beispiel des kommunalen Umweitschutzes in der Nordwestschweiz», en Gesetzgebung heute / Législation d'ajourd'hui / Legilazione oggi / Legislaziun dad oz, 1999/1, pp. 108 y 109.

147 Vid. FleINER, «Art. $24^{\text {septies }_{\rangle}}$op. cit., p. 20.

148 Vid. NiCOLE, L'étude d'impact... op. cit., pp. 86 y 87.

149 Vid. FleINER, «Umweltschutz- und Raumplanungsrecht» op. cit., p. 111.

150 Vid. Nicole, L'étude d'impact... op. cit., p. 87.

151 Vid. PetitPierRe, Environmental Law... op. cit., p. 37.
} 
cución cantonal, admitiéndose la posibilidad excepcional de la intervención federal ${ }^{152}$. Así, el artículo 36LPMA atribuye a los cantones la ejecución de la ley, sometiéndola en todo caso a la reserva del artículo $41^{153}$. La ejecución cantonal, eso sí, está sometida a la supervisión de la Confederación, tal y como se desprende del artículo 38. 1LPMA ${ }^{154}$. Por otra parte, la Confederación, de acuerdo con el artículo 56. 1LPMA, está habilitada, a través del Departamento federal de Interior, para recurrir, tanto en el ámbito cantonal como en el federal, las decisiones de las autoridades cantonales fundadas en las atribuciones relativas a la ejecución de la ley y de las normas que la desarrollen. El control también puede ser impulsado por los cantones vecinos, de acuerdo con el párrafo segundo del mismo artículo.

Por último, en cuanto a la ejecución, debe tenerse en cuenta el tercer nivel de poder político en Suiza, a saber, las comunas, cuya autonomía ha sido constitucionalizada en la revisión total de 1999 (art. 50.ICF). Esta Administración también tiene un cierto papel en la ejecución de la política ambiental, aunque, en definitiva, se trata de una intervención más bien residual, destinada a rellenar los vacíos que, eventualmente, puedan dejar las autoridades federales y cantonales. Sin embargo, como hace notar Alfred KUTTLER, no podemos olvidar que, en última instancia, las comunas acaban teniendo en papel clave en la realización de la política ambiental y de ordenación del territorio. No cabe duda de que la acción municipal en estos terrenos viene predeterminada por la existencia de una ingente normativa, tanto a nivel federal como a nivel cantonal, hasta el punto de que puede parecer que no hay espacio para una política autónoma comunal. Sin embargo, a pesar de este fuerte condi-

\footnotetext{
${ }^{152}$ La primacía de los cantones en cuanto a la ejecución la destaca NICOLE, en L'étude d'impact... op. cit., p. 105.

153 El párrafo primero del artículo 41LPMA prevé que la Confederación ejecutará las prescripciones de la ley relativas a combustibles y carburantes (art. 12.1LPMA), control autónomo (art. 26), información al consumidor (art. 27LPMA), prescripciones sobre las sustancias (art. 29LPMA), organismos peligrosos para el medio ambiente (arts. 29b a 29hLPMA), caja de compensación relativa a la consigna (art. 30b.3LPMA), importación y exportación de residuos (arts. 30f a 30gLPMA), eliminación de residuos a nivel federal (arts. 31 a.2 i 31.c.3LPMA), tasa de eliminación anticipada (art. 31abis), otras tasas (art. 32e.1 i 4LPMA), tasas de incitación (arts. 35a a 35cLPMA), prescripciones de ejecución y acuerdos internacionales (art. 39LPMA), puesta en el mercado de instalaciones fabricadas en serie (art. 40LPMA), y información sobre las sustancias y los organismos (art. 46.3LPMA). El segundo párrafo del artículo citado establece que la autoridad federal que ejecuta otra ley federal o un tratado internacional es, en relación con el cumplimiento de esa tarea, responsable de la aplicación de la LPMA, aunque deberá consultar a los cantones afectados.

154 Así lo pone de manifiesto Nicole, en L'étude d'impact... op. cit., p. 112. El mismo autor explicita el alcance de la supervisión en las páginas siguientes a la que acabamos de citar.
} 
cionamiento normativo, las comunas acaban teniendo un papel importante en la ejecución ${ }^{155}$.

\section{CONCLUSIONES}

A partir de lo que se ha dicho en las líneas precedentes, pueden extraerse cuatro conclusiones fundamentales. En primer lugar, la introducción de la protección del medio ambiente como materia competencial en el texto constitucional federal responde a una finalidad centralizadora de la política ambiental. Esta centralización es, de hecho, paralela a la que se produce en el mismo momento en otros estados compuestos, como lo muestra, en particular, el ejemplo de los Estados Unidos. En segundo, lugar, debe notarse que la competencia atribuida, a la federación en la Constitución es, fundamentalmente, de carácter normativo, quedando, con carácter general, la ejecución en manos de los cantones. Por otra parte, la competencia atribuida por la Constitución a la federación no se reduce a una facultad le intervención, sino que incorpora un mandato, a pesar de que la inexistencia de un control de constitucionalidad de la actividad del parlamento federal en Suiza matiza en gran medida esto último. En cuarto y último lugar, debe notarse que, a pesar de que, en principio, la competencia normativa, en materia de medio ambiente, corresponde, de acuerdo con el artículo 74CF, a la Confederación, el hecho es que los cantones acaban disponiendo de un cierto margen de maniobra para aprobar normas ambientales. Inversamente, aunque la ejecución corresponda primariamente a los cantones, la federación puede reservarse y, de hecho, lo hace, una parte de la ejecución de su propia legislación en materia de medio ambiente. Así, la política ambiental acaba realizándose tanto a nivel federal como cantonal, sin que, aparentemente, se hayan producido demasiados conflictos en relación con ello.

\footnotetext{
155 Vid. Alfred KuttLeR, «Aménagement du territoire et protection de l'environnement per les comunes: quelques expériences d'un juge fédéral», en Baurecht / Droit de la Construction, n. ${ }^{\circ} 2$, 1992, p. 27.
} 